PALABRAS CLAVE

Pobreza

Distribución del ingreso

Medición

Ajuste estructural

America Latina
Oscar Altimir

Director de la Revista

de la CEPAL (1996-2008)
REVISTA DE LA CEPAL 96 DICIEMBRE 2008

\section{Distribución del ingreso e incidencia de la pobreza a lo largo del ajuste}

\author{
Oscar Altimir
}

$\mathrm{E}$

ste artículo analiza los costos distributivos de la crisis y los ajustes de los años ochenta, así como los efectos de la recuperación y del inicio de sendas de crecimiento sostenido. Para ello se basa en pares comparables de estimaciones de la distribución del ingreso y en las estimaciones de pobreza de la CEPAL para los diez países mayores de la región, predominantemente urbanos. El método de análisis consiste, por un lado, en comparar los cambios distributivos y los cambios en las variables macroeconómicas y del mercado de trabajo durante fases macroeconómicas similares a lo largo del proceso de ajuste en diferentes países y, por otro, en comparar las situaciones distributivas en cada país, antes y después del ajuste. Se concluye que, si bien la recuperación económica y el abatimiento de la inflación están aliviando las situaciones de pobreza, el crecimiento de mediano plazo sin mejoramiento de la distribución del ingreso traerá un proceso demasiado largo de reducción de la pobreza, y que hay bases para suponer que la nueva modalidad de funcionamiento y las nuevas reglas de política pública de estas economías pueden implicar mayores desigualdades de ingreso. 


\section{I}

\section{Introducción}

La mayoría de los países de América Latina están recuperándose arduamente de la prolongada crisis que padecieron durante los años ochenta y de los ajustes traumáticos por los que tuvieron que pasar para liberarse de ella y establecer las bases de una nueva fase de crecimiento sostenido.

La transferencia neta de recursos hacia la región, que antes de la crisis representaba más de $2 \%$ de su PIB, súbitamente se volvió negativa. Entre 1982 y 1989 la exportación neta de capital de los países de América Latina fue equivalente a casi $4 \%$ de su PIB agregado. El cambio en la transferencia neta de recursos equivalió a una presión permanente de $6 \%$ sobre los recursos internos durante el período.

Después del ajuste externo y la recesión que redujeron en $10 \%$ el producto per cápita entre 1980 y 1983, la mayor parte de las economías de América Latina oscilaron entre la recesión y la inflación y enfrentaron como pudieron el problema de la deuda y sus consecuencias internas durante la mayor parte del decenio. Al finalizar la crisis, el producto per cápita aún se situaba al nivel de 1983 y el ingreso nacional real per cápita era $15 \%$ inferior al de 1980. Sin embargo, durante 1991-1993 el crecimiento fue más constante, hubo señales de reactivación de la inversión privada junto con el regreso de importantes corrientes de capital, se generalizó la tendencia a la estabilización de los precios y la mayor parte de los enormes ajustes fiscales de los años anteriores logró mantenerse.

Aunque en algunos casos los procesos de estabilización todavía muestran cierta fragilidad, la mayor parte de las economías de América Latina se asienta sobre bases nuevas. Estas se caracterizan por una orientación más firme hacia las exportaciones (cuyo volumen, en muchos casos, al menos se duplicó durante el pasado decenio), la liberalización del comercio, la austeridad fiscal, una gestión más prudente de la política monetaria y mayor renuencia a recurrir a la regulación estatal de la actividad económica.

Para los grupos pobres y de ingresos medianos bajos, la grave crisis económica de los años ochenta significó un deterioro tanto del ingreso real como del acceso y la calidad de los servicios sociales.

Casi todos los países experimentaron una pronunciada redistribución del ingreso entre los hogares durante ese decenio, en la mayoría de los casos con resultados regresivos netos al final de él. Por otra parte, los cambios regresivos en el ingreso relativo y la caída del ingreso real per cápita durante la primera mitad del decenio, cuando la mayor parte de las economías experimentaba ajustes recesivos o había apenas empezado a recuperarse, significaron incrementos importantes de la pobreza absoluta, que solo en unos cuantos casos lograron anularse parcialmente con los procesos de estabilización y crecimiento de los últimos años.

La recuperación económica y el descenso de la inflación en algo mejoraron la situación en cuanto a la pobreza; sin embargo, cunde la sensación de que la nueva modalidad de funcionamiento de las economías y las nuevas reglas de política pública suponen, en relación con el pasado, mayores desigualdades de ingreso y situaciones más precarias en cuanto a empleo en un entorno fiscal ciertamente más restrictivo. $\square$ El autor agradece los valiosos comentarios de Robert Devlin, Norberto García y Arturo León, así como la experta colaboración de
Gloria Bensan y Guillermo Mundt, sin que ello signifique responsabilidad alguna de su parte por los resultados finales. 


\section{II}

\section{El método de trabajo}

\section{La base de datos sobre la distribución del in- greso y la pobreza}

La confiabilidad de las estadísticas sobre distribución del ingreso en América Latina es muy variable, y estas no pueden compararse directamente entre sí. ${ }^{1}$
Muchos son los factores que distorsionan su comparabilidad; entre ellos, la subestimación del ingreso afecta de manera diferente tanto los niveles de ingreso como su concentración. Para obviar de alguna manera este obstáculo, el análisis de los cambios en la distribución relativa del ingreso se basa en pares de estimaciones CUADRO 1

\section{América Latina (10 países): Cambios en la distribución del ingreso en períodos seleccionados}

\begin{tabular}{|c|c|c|c|c|c|c|c|c|c|}
\hline \multirow[b]{2}{*}{ Países } & \multirow[b]{2}{*}{ Períodos } & \multirow[b]{2}{*}{ Fuentes } & \multirow[b]{2}{*}{ Cobertura $^{\mathrm{a}}$} & \multirow[b]{2}{*}{$\begin{array}{l}\text { Conceptos } \\
\text { de ingreso }\end{array}$} & \multicolumn{2}{|c|}{$\begin{array}{l}\text { Cambios en la } \\
\text { concentración } \\
\text { (porcentajes) }\end{array}$} & \multicolumn{3}{|c|}{$\begin{array}{l}\text { Cambios en la participación } \\
\text { de los grupos de ingreso } \\
\text { (porcentaje del ingreso total) }\end{array}$} \\
\hline & & & & & $\begin{array}{l}\text { Coeficiente } \\
\text { Gini }\end{array}$ & $\begin{array}{l}\text { Coeficiente } \\
10 \% \text { de ingr. } \\
\text { + alto y } 40 \% \\
\text { de ingr. + bajo }\end{array}$ & $\begin{array}{l}40 \% \\
\text { bajo }\end{array}$ & $\begin{array}{c}50 \% \\
\text { intermedio }\end{array}$ & $10 \%$ alto \\
\hline \multirow[t]{5}{*}{ Argentina } & $1970-1974$ & Altimir (1986) & $\mathrm{AM}$ & $\mathrm{IH}$ & 4 & 9 & $-0,7$ & $-0,7$ & 1,4 \\
\hline & $1974-1980$ & Altimir (1986) & $\mathrm{AM}$ & $\mathrm{IPCH}$ & 10 & 28 & $-2,1$ & $-1,2$ & 3,3 \\
\hline & $1980-1986$ & CEPAL (1991b) & $\mathrm{AM}$ & $\mathrm{IPCH}$ & 11 & 27 & $-1,5$ & $-3,2$ & 4,7 \\
\hline & 1980-1989 & $\begin{array}{r}\text { Psacharopoulos } \\
\text { y otros (1992) }\end{array}$ & $\mathrm{AM}$ & IPCH & 17 & 47 & $-2,9$ & $-3,0$ & 5,9 \\
\hline & $1985-1990$ & Beccaria (1991) & $\mathrm{AM}$ & $\mathrm{IPCH}$ & $\ldots$ & $33^{c}$ & $-1,4^{\mathrm{d}}$ & $-3,4^{\mathrm{e}}$ & 4,8 \\
\hline \multirow[t]{7}{*}{ Brasil } & $1979-1987$ & CEPAL (1991b) & $\mathrm{AM}$ & $\mathrm{IPCH}$ & 4 & 32 & $-2,3$ & $-1,3$ & 3,6 \\
\hline & & & $\mathrm{RU}$ & IPCH & 7 & 9 & 2,7 & $-5,5$ & 2,8 \\
\hline & 1979-1989 & $\begin{array}{l}\text { Psacharopoulos } \\
\text { y otros (1992) }\end{array}$ & $\mathrm{N}$ & $\mathrm{IPCH}$ & 7 & 28 & $-1,3$ & $-2,4$ & 3,7 \\
\hline & 1987-1989 & Hoffman (1992) & $\mathrm{U}$ & IR & 8 & $31^{\mathrm{f}}$ & $-2,1^{\mathrm{g}}$ & $-2,8^{\mathrm{h}}$ & 4,9 \\
\hline & $1987-1990$ & Hoffman (1992) & $\mathrm{U}$ & IR & 2 & 9 & $-1,0$ & - & 1,0 \\
\hline & $1987-1990$ & CEPAL $(1991 b ; 1993)$ & $\mathrm{AM}$ & $\mathrm{IPCH}$ & -6 & -18 & 0,4 & 6,3 & $-6,7$ \\
\hline & & & $\mathrm{RU}$ & $\mathrm{IPCH}$ & 1 & 53 & $-5,1$ & 5,2 & $-0,1$ \\
\hline \multirow[t]{6}{*}{ Colombia } & 1978-1988 & Londoño (1990) & $\mathrm{N}$ & IR & -1 & -3 & $-0,2$ & 0,3 & $-0,5$ \\
\hline & 1980-1986 & CEPAL (1991b) & $\mathrm{AM}$ & $\mathrm{IPCH}$ & -3 & -12 & 0,2 & 0,8 & -1 \\
\hline & & & $\mathrm{RU}$ & $\mathrm{IPCH}$ & -5 & $\cdots$ & 0,4 & 3,0 & $-3,4$ \\
\hline & 1980-1989 & $\begin{array}{l}\text { Psacharopoulos } \\
\text { y otros (1992) }\end{array}$ & $\mathrm{U}$ & $\mathrm{IPCH}$ & -9 & -27 & 1,9 & 3,2 & $-5,1$ \\
\hline & $1986-1990$ & CEPAL $(1991 b ; 1993)$ & $\mathrm{AM}$ & $\mathrm{IPCH}$ & -2 & -1 & $-0,4$ & 2,7 & $-2,3$ \\
\hline & & & $\mathrm{RU}$ & $\mathrm{IPCH}$ & -9 & -2 & 1,9 & 1,4 & $-3,3$ \\
\hline \multirow[t]{5}{*}{ Costa Rica } & 1981-1988 & CEPAL (1991b) & $\mathrm{AM}$ & IPCH & 7 & 22 & $-1,5$ & $-1,6$ & 3,1 \\
\hline & & & $\mathrm{RU}$ & $\mathrm{IPCH}$ & 14 & 3 & $-1,9$ & $-3,2$ & 5,1 \\
\hline & 1981-1989 & $\begin{array}{l}\text { Psacharopoulos } \\
\text { y otros (1992) }\end{array}$ & $\mathrm{N}$ & $\mathrm{IPCH}$ & -3 & -10 & 1,4 & $-1,9$ & 0,5 \\
\hline & $1988-1990$ & CEPAL $(1991 b ; 1993)$ & $\mathrm{AM}$ & $\mathrm{IPCH}$ & -6 & -13 & 1,1 & 1,1 & $-2,2$ \\
\hline & & & $\mathrm{RU}$ & IPCH & -6 & -15 & 0,4 & 3,0 & $-3,4$ \\
\hline
\end{tabular}

${ }^{1}$ Véase en Altimir (1987) un análisis de la confiabilidad de la medición del ingreso a partir de diferentes tipos de encuestas en América Latina y de sus problemas de comparabilidad. 
CUADRO 1 (continuación)

\begin{tabular}{|c|c|c|c|c|c|c|c|c|c|}
\hline \multirow[b]{2}{*}{ Países } & \multirow[b]{2}{*}{ Períodos } & \multirow[b]{2}{*}{ Fuentes } & \multirow[b]{2}{*}{ Cobertura $^{\mathrm{a}}$} & \multirow[b]{2}{*}{$\begin{array}{l}\text { Conceptos } \\
\text { de ingreso }\end{array}$} & \multicolumn{2}{|c|}{$\begin{array}{l}\text { Cambios en la } \\
\text { concentración } \\
\text { (porcentajes) }\end{array}$} & \multicolumn{3}{|c|}{$\begin{array}{l}\text { Cambios en la participación } \\
\text { de los grupos de ingreso } \\
\text { (porcentaje del ingreso total) }\end{array}$} \\
\hline & & & & & $\begin{array}{l}\text { Coeficiente } \\
\text { Gini }\end{array}$ & $\begin{array}{c}\text { Coeficiente } \\
10 \% \text { de ingr. }+ \\
\text { alto y } 40 \% \text { de } \\
\text { ingr. + bajo }\end{array}$ & $\begin{array}{l}40 \% \\
\text { bajo }\end{array}$ & $\begin{array}{c}50 \% \\
\text { intermedio }\end{array}$ & $10 \%$ alto \\
\hline \multirow[t]{7}{*}{ Chile } & $1968-1974$ & Heskia (1980) & $\mathrm{AM}$ & $\mathrm{IH}$ & -10 & -23 & 2 & 1,8 & $-3,8$ \\
\hline & $1974-1980$ & $\begin{array}{l}\text { Heskia (1980), } \\
\text { Riveros (1985) }\end{array}$ & $\mathrm{AM}$ & $\mathrm{IH}$ & 21 & 60 & $-2,8$ & $-6,2^{\mathrm{h}}$ & $9,0^{\mathrm{i}}$ \\
\hline & $1981-1983$ & Riveros (1985) & $\mathrm{AM}$ & $\mathrm{IH}$ & 2 & 14 & $-1,1$ & $-0,5^{\mathrm{h}}$ & $1,6^{\mathrm{i}}$ \\
\hline & $1968-1983$ & $\begin{array}{l}\text { CEPAL (1979), } \\
\text { Rodríguez (1985) }\end{array}$ & $\mathrm{N}$ & $\mathrm{IH}$ & 23 & 38 & $-1,6$ & $-6,2$ & 7,8 \\
\hline & $1969-1978$ & $\begin{array}{l}\text { Ffrench-Davis, } \\
\text { Raczynski (1987) }\end{array}$ & $\mathrm{AM}$ & $\mathrm{GH}$ & $\ldots$ & $54^{\mathrm{j}}$ & $-4,9$ & $-1,6^{\mathrm{h}}$ & $6,5^{\mathrm{i}}$ \\
\hline & $1978-1988$ & $\begin{array}{l}\text { Ffrench-Davis, } \\
\text { Raczynski(1987) }\end{array}$ & $\mathrm{AM}$ & $\mathrm{GH}$ & $\ldots$ & $23^{j}$ & $-1,9$ & $-1,7^{\mathrm{h}}$ & $3,6^{\mathrm{i}}$ \\
\hline & $1987-1990$ & CEPAL $(1991 b ; 1991 c)$ & $\mathrm{U}$ & IPC I I & -2 & -3 & 0,4 & $-0,4$ & $\cdots$ \\
\hline \multirow[t]{2}{*}{ México } & $1977-1984$ & $\begin{array}{l}\text { CEPAL (1988), } \\
\quad \text { Lustig (1992) }\end{array}$ & $\mathrm{N}$ & $\mathrm{IH}$ & -9 & -41 & 2,8 & 0,7 & $-3,5$ \\
\hline & 1984-1989 & Lustig (1992) & $\mathrm{N}$ & $\mathrm{IH}$ & $\ldots$ & 28 & $-1,4$ & $-3,7$ & 5,1 \\
\hline Panamá & 1979-1989 & $\begin{array}{l}\text { Psacharopoulos } \\
\text { y otros (1992) }\end{array}$ & $\mathrm{N}$ & $\mathrm{IPCH}$ & 16 & 66 & $-3,5$ & $-2,8$ & 6,3 \\
\hline Perú & $\begin{array}{l}1985-1986- \\
1990\end{array}$ & $\begin{array}{r}\text { Psacharopoulos } \\
\text { y otros (1992) }\end{array}$ & $\mathrm{AM}$ & $\mathrm{IPCH}$ & 2 & 5 & $-0,7$ & 0,5 & 0,2 \\
\hline \multirow[t]{6}{*}{ Uruguay } & $1973-1979$ & Melgar (1981), & $\mathrm{AM}$ & IPH & 32 & 100 & $-4,7$ & $-8,3$ & 13,0 \\
\hline & $1979-1981$ & $\begin{array}{l}\text { Melgar (1981), } \\
\text { Melgar-Villalobos } \\
\text { (1987) }\end{array}$ & $\mathrm{AM}$ & IPH & -2 & -4 & $-1,2$ & 6,3 & $-5,1$ \\
\hline & 1981-1986 & CEPAL (1991a; 1991b) & $\mathrm{AM}$ & $\mathrm{IPCH}$ & 7 & 20 & $-1,2$ & $-2,4$ & 3,6 \\
\hline & 1986-1989 & CEPAL (1991a; 1991b) & $\mathrm{AM}$ & $\mathrm{IPCH}$ & -9 & -19 & 1,4 & 3,1 & $-4,5$ \\
\hline & & & $\mathrm{RU}$ & $\mathrm{IPCH}$ & -7 & -12 & 1,5 & 0,1 & $-1,6$ \\
\hline & 1981-1989 & $\begin{array}{r}\text { Psacharopoulos } \\
\text { y otros (1992) }\end{array}$ & $\mathrm{U}$ & $\mathrm{IPCH}$ & -3 & -7 & 0,8 & $-0,2$ & $-0,6$ \\
\hline \multirow[t]{7}{*}{ Venezuela } & $1981-1986$ & CEPAL (1991b) & $\mathrm{AM}$ & $\mathrm{IPCH}$ & 8 & 19 & $-2,5$ & $-1,7$ & 4,2 \\
\hline & & & $\mathrm{RU}$ & $\mathrm{IPCH}$ & 18 & 46 & $-2,6$ & $-3,1$ & 5,7 \\
\hline & 1981-1989 & $\begin{array}{r}\text { Psacharopoulos } \\
\text { y otros (1992) }\end{array}$ & $\mathrm{N}$ & $\mathrm{IPCH}$ & 3 & 8 & $-0,4$ & $-1,3$ & 1,7 \\
\hline & $1986-1990$ & CEPAL $(1991 b ; 1993)$ & $\mathrm{AM}$ & $\mathrm{IPCH}$ & -4 & -7 & 0,8 & $-0,4$ & $-0,4$ \\
\hline & & & $\mathrm{RU}$ & $\mathrm{IPCH}$ & - & 3 & - & $-0,6$ & 0,6 \\
\hline & 1987-1989 & $\begin{array}{l}\text { Márquez-Mukherjee } \\
\text { (1991) }\end{array}$ & $\mathrm{N}$ & IPCH & 6 & 11 & $-0,2$ & $-3,5$ & 3,7 \\
\hline & 1989-1990 & $\begin{array}{l}\text { Márquez-Mukherjee } \\
\text { (1991) }\end{array}$ & $\mathrm{N}$ & $\mathrm{IPCH}$ & -4 & -14 & 0,9 & 1,8 & $-2,7$ \\
\hline \multicolumn{4}{|c|}{$\begin{array}{l}\text { aM: área metropolitana; RU: resto de áreas urbanas; U: áreas urbanas; } \\
\text { N: nacional. }\end{array}$} & $\begin{array}{lll}\text { e } & \mathrm{C} \\
\mathrm{f} & \mathrm{R}\end{array}$ & $\begin{array}{l}\text { Corresponde a } \\
\text { Relación } 10 \text { al }\end{array}$ & $\begin{array}{l}\text { al } 60 \% \text { intermedio } \\
\text { lto/ } 50 \text { bajo. }\end{array}$ & & & \\
\hline 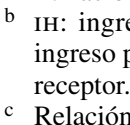 & $\begin{array}{l}\text { o del hogar; } \\
\text { r cápita del ho }\end{array}$ & $\begin{array}{l}\text { H: ingreso primario de } \\
\text { ar; GH: gastos del hogar; }\end{array}$ & $\begin{array}{l}\text { el hogar; IPC } \\
\text {; IR: ingreso } \mathrm{d}\end{array}$ & $\begin{array}{ll}\mathrm{g} & \mathrm{C} \\
\mathrm{h} & \mathrm{C} \\
\mathrm{i} & \mathrm{C}\end{array}$ & $\begin{array}{l}\text { Corresponde a } \\
\text { Corresponde a } \\
\text { Corresponde a }\end{array}$ & $\begin{array}{l}\text { al } 50 \% \text { inferior. } \\
\text { al } 40 \% \text { intermedio } \\
\text { al } 20 \% \text { superior. }\end{array}$ & & & \\
\hline $\begin{array}{ll}\text { c } & \text { Relación } \\
\text { d } & \text { Correspo }\end{array}$ & $\begin{array}{l}10 \text { alto/30 baj } \\
\text { de al } 30 \% \text { inf }\end{array}$ & & & $\mathrm{j} \quad \mathrm{R}$ & Relación 20 al & lto/40 bajo. & & & \\
\hline
\end{tabular}


América Latina: ${ }^{a}$ Estimaciones de pobreza e indigencia en 1980, 1986 y 1990

\begin{tabular}{|c|c|c|c|c|c|c|c|c|c|c|c|c|}
\hline \multirow[b]{3}{*}{ Área } & \multicolumn{6}{|c|}{ Pobreza ${ }^{\mathrm{b}}$} & \multicolumn{6}{|c|}{ Indigencia $^{c}$} \\
\hline & \multicolumn{2}{|c|}{1980} & \multicolumn{2}{|c|}{1986} & \multicolumn{2}{|c|}{1990} & \multicolumn{2}{|c|}{1980} & \multicolumn{2}{|c|}{1986} & \multicolumn{2}{|c|}{1990} \\
\hline & Millones & $\%$ & Millones & $\%$ & Millones & $\%$ & Millones & $\%$ & Millones & $\%$ & Millones & $\%$ \\
\hline \multicolumn{13}{|c|}{ Hogares } \\
\hline Nacional & 24,2 & 35 & 32,1 & 37 & 37,0 & 39 & 10,4 & 15 & 14,6 & 17 & 16,9 & 18 \\
\hline Urbana & 11,8 & 25 & 18,7 & 30 & 22,7 & 34 & 4,1 & 9 & 7,0 & 11 & 8,7 & 13 \\
\hline Rural & 12,4 & 54 & 13,4 & 53 & 14,3 & 53 & 6,3 & 28 & 7,6 & 30 & 8,2 & 30 \\
\hline \multicolumn{13}{|c|}{ Personas } \\
\hline Nacional & 135,9 & 41 & 170,2 & 43 & 195,9 & 46 & 62,4 & 19 & 81,4 & 21 & 93,5 & 22 \\
\hline Urbana & 62,9 & 30 & 94,4 & 36 & 115,5 & 39 & 22,5 & 11 & 35,8 & 14 & 44,9 & 15 \\
\hline Rural & 73,0 & 60 & 75,8 & 60 & 80,4 & 61 & 39,9 & 33 & 45,6 & 36 & 48,6 & 37 \\
\hline
\end{tabular}

Fuente: Para 1980 y 1986: CEPAL, 1991a. Para 1990: CEPAL, 1992a.

a 19 países. Basadas en datos de: Argentina, Brasil, Colombia, Costa Rica, Guatemala, México, Panamá, Perú, Uruguay y Venezuela para 1980 y 1986, y también de Chile, Honduras y Paraguay para 1990.

b Corresponde al ingreso per cápita de los hogares por debajo de las líneas de pobreza equivalentes al doble de los presupuestos alimentarios mínimos específicos por países, que varían de 22 a 34 dólares de 1988 por persona al mes, para las áreas urbanas.

c Corresponde al ingreso per cápita de los hogares por debajo del valor de los presupuestos alimentarios mínimos específicos por países utilizados para trazar las líneas de pobreza.

disponibles (que pueden verse en el cuadro 1), elegidas por su similitud (y, por consiguiente, su aparente comparabilidad) respecto del concepto de ingreso, la técnica de medición del ingreso y la cobertura geográfica de las encuestas utilizadas para recopilar los datos, así como respecto de las unidades y criterios utilizados por los autores respectivos al procesar o ajustar los datos de las encuestas. ${ }^{2}$ Sin embargo, las diferencias corroboradas o supuestas respecto de cualquiera de estos aspectos invalidan en muchos casos ir más allá de estas comparaciones de pares para utilizar simplemente un fondo común (pooling) de estimaciones.

Las estimaciones de la pobreza (cuadro 2) corresponden a las producidas por la CEPAL (1991a y 1992a). Son el resultado de cortar las distribuciones estimadas de los hogares según su ingreso per cápita, previamente ajustado para tener en cuenta una subestimación de ingreso, ${ }^{3}$ mediante líneas de pobreza específicas por países; estas representan presupuestos normativos mínimos del consumo privado basados en presupuestos alimentarios mínimos que cubren adecuadamente las necesidades

\footnotetext{
${ }^{2}$ Véase en Altimir (1992) una compilación detallada de las estadísticas sobre distribución del ingreso en cada país y la selección de pares comparables. En particular, la selección basada en la similitud de los datos y su tratamiento permite comparar los coeficientes de Gini (y calcular sus variaciones, como se hace en el cuadro 1), que se han computado sobre la base de datos agrupados en forma similar.

${ }^{3}$ Véase el método del ajuste aplicado en Altimir (1987) y los detalles de los ajustes en CEPAL (1991a).
}

nutricionales. ${ }^{4}$ Las líneas de pobreza utilizadas para los diversos años del decenio de 1980 se mantuvieron constantes en términos reales, criterio aceptable para un período de recesión y recuperación. ${ }^{5}$

En el presente artículo se utilizan como medida de la pobreza solamente relaciones de incidencia (headcount ratios), correspondientes a varios años del último decenio con respecto a cada país estudiado. ${ }^{6}$ Se muestran en el cuadro 3, que también incluye la incidencia de la extrema pobreza o indigencia, definida como la proporción de hogares con un ingreso per cápita menor que el valor del presupuesto alimentario mínimo.

\footnotetext{
${ }^{4}$ Véanse en CEPAL (1991a) los detalles acerca de los presupuestos alimentarios mínimos específicos por países y la manera cómo se establecieron. Las canastas mínimas de alimentos se obtuvieron sobre la base de la composición del consumo de alimentos de los estratos de hogares que en cada país alcanzaron con cierta amplitud las necesidades nutricionales mínimas, aunque estas canastas de referencia se ajustaron a esos mínimos así como a la disponibilidad media nacional de cada alimento, excluyendo aquellos artículos de un alto precio por caloría o de un valor nutricional superfluo. Por consiguiente, el criterio para establecer las canastas mínimas de alimentos se basó en los hábitos, teniendo en cuenta la disponibilidad y el costo, más que en el costo mínimo, teniendo en cuenta la disponibilidad y los hábitos, como hizo Altimir (1979) a fin de obtener las estimaciones para 1970.

5 Véase en Altimir (1991) un análisis de los argumentos en favor de desplazar las líneas de pobreza a lo largo de períodos de crecimiento económico.

${ }^{6}$ En CEPAL (1991a) también se incluyen estimaciones de las brechas de pobreza, pero solo para 1986.
} 
CUADRO 3

América Latina (10 países): Incidencia de la pobreza y de la indigencia en los años ochenta

(Porcentajes de hogares)

\begin{tabular}{|c|c|c|c|c|c|c|}
\hline \multirow{4}{*}{$\begin{array}{c} \\
\text { Argentina } \\
1980\end{array}$} & \multicolumn{3}{|c|}{ Pobreza } & \multicolumn{3}{|c|}{ Indigencia } \\
\hline & \multirow{2}{*}{ Areas urbanas } & \multirow[t]{2}{*}{ Areas rurales } & \multirow[t]{2}{*}{ Nivel nacional } & \multirow[t]{2}{*}{ Areas urbanas } & \multirow{2}{*}{ Areas rurales } & \multirow[t]{2}{*}{ Nivel nacionales } \\
\hline & & & & & & \\
\hline & 7 & $16^{\mathrm{a}}$ & 9 & 2 & $4^{\mathrm{a}}$ & 2 \\
\hline 1986 & 12 & $17^{\mathrm{a}}$ & 13 & 3 & $6^{\mathrm{a}}$ & 4 \\
\hline 1990 & $19^{\mathrm{b}}$ & & & & & \\
\hline 1991 & $15^{\mathrm{b}}$ & & & & & \\
\hline \multicolumn{7}{|l|}{ Brasil } \\
\hline 1979 & 30 & 62 & 39 & 10 & 35 & 17 \\
\hline 1987 & 34 & 60 & 40 & 13 & 34 & 18 \\
\hline 1990 & 39 & 56 & 43 & 17 & 31 & 20 \\
\hline \multicolumn{7}{|l|}{ Colombia } \\
\hline 1980 & 36 & $45^{\mathrm{a}}$ & 39 & 13 & $22^{\mathrm{a}}$ & 16 \\
\hline 1986 & 36 & 42 & 38 & 15 & 22 & 17 \\
\hline 1990 & 35 & 12 & & & & \\
\hline \multicolumn{7}{|l|}{ Costa Rica } \\
\hline 1981 & 16 & 28 & 22 & 5 & 8 & 6 \\
\hline 1988 & 21 & 28 & 25 & 6 & 10 & 10 \\
\hline 1990 & 22 & 25 & 24 & 7 & 12 & 10 \\
\hline \multicolumn{7}{|l|}{ Chile } \\
\hline 1980 & $32^{\mathrm{c}}$ & $41^{\mathrm{c}}$ & $33^{\mathrm{c}}$ & & & \\
\hline 1987 & 37 & 45 & 38 & 13 & 16 & 14 \\
\hline 1990 & 34 & 36 & 35 & 11 & 15 & 12 \\
\hline \multicolumn{7}{|l|}{ México } \\
\hline 1977 & 32 & 10 & & & & \\
\hline 1984 & 23 & 43 & 30 & 6 & 19 & 10 \\
\hline \multicolumn{7}{|l|}{ Panamá } \\
\hline 1979 & 31 & 45 & 36 & 14 & 27 & 19 \\
\hline 1986 & 30 & 43 & 34 & 13 & 22 & 16 \\
\hline 1989 & 34 & 48 & 38 & 15 & 25 & 18 \\
\hline \multicolumn{7}{|l|}{ Perú } \\
\hline 1979 & 35 & $65^{\mathrm{a}}$ & 46 & 10 & $38^{\mathrm{a}}$ & 21 \\
\hline $1985 / 86$ & 45 & 64 & 52 & 16 & 39 & 25 \\
\hline \multicolumn{7}{|l|}{ Uruguay } \\
\hline 1981 & 9 & $21^{\mathrm{a}}$ & 11 & 2 & $7^{\mathrm{a}}$ & 3 \\
\hline 1986 & 14 & $23^{\mathrm{a}}$ & 15 & 3 & $8^{\mathrm{a}}$ & 3 \\
\hline 1989 & 10 & $23^{\mathrm{a}}$ & 15 & 2 & $8^{\mathrm{a}}$ & 3 \\
\hline \multicolumn{7}{|l|}{ Venezuela } \\
\hline 1981 & 18 & 35 & 22 & 5 & 15 & 7 \\
\hline 1986 & 25 & 34 & 27 & 8 & 14 & 9 \\
\hline 1990 & 33 & 38 & 34 & 11 & 17 & 12 \\
\hline
\end{tabular}

Fuente: CEPAL (1991a, 1991b; 1992a).

a Estas estimaciones deben considerarse como "conjeturas informadas" basadas en informaciones pertinentes pero indirectas.

b Estimaciones del autor, basadas en Beccaria y Minujin (1991).

c Estimaciones del autor, basadas en Pollack y Uthoff (1987). Véase Altimir (1991). 
Estas estimaciones de hecho construyen mediciones nacionales de la pobreza a partir de estimaciones urbanas y rurales. Sin embargo, cabe tener presente que las estimaciones de la incidencia de la pobreza en las zonas rurales son de una calidad considerablemente menor que las estimaciones para las áreas urbanas. Por una parte, las normas utilizadas para trazar la línea de pobreza tienen un sesgo urbano inevitable, no obstante que se toman en cuenta las diferencias entre zonas urbanas y rurales en materia de precios y consumo. Por otra parte, las mediciones existentes del ingreso rural y su distribución generalmente son aún menos precisas que las del ingreso urbano de la misma encuesta. Finalmente, algunas de las estimaciones rurales son solo "conjeturas informadas" basadas en datos pertinentes pero indirectos (Altimir, 1991).

El conjunto de países estudiados en el presente trabajo incluye los más importantes de América Latina, así como otros respecto de los cuales se dispone también de mediciones comparables de desigualdad y pobreza tanto al comienzo del decenio como en un período posterior. Se excluyen los países predominantemente rurales, como Guatemala y Honduras, para los que la CEPAL produjo asimismo estimaciones de la pobreza, debido a que el método de análisis utilizado en esta ocasión y las variables sobre las que se funda recogen más que nada fenómenos urbanos. La sola dimensión de la pobreza rural, según esas estimaciones (afecta a las cuatro quintas partes de la población rural y representa al menos las tres cuartas partes de todos los pobres), subraya la falta de pertinencia en tales casos de un análisis centrado en las zonas urbanas y sugiere que la medición y el análisis de la pobreza en esos países debe basarse en encuestas, criterios de pobreza y variables explicativas relacionados más estrechamente con las condiciones rurales.

En esta base de datos el ingreso mide generalmente aquél en efectivo ${ }^{7}$ disponible en los hogares, incluidos los ingresos primarios (sueldos y salarios e ingresos empresariales) y otros ingresos monetarios (pensiones, transferencias, alquileres, intereses, etc.) después del pago de los impuestos directos. Por consiguiente, excluye el ingreso imputado proveniente de bienes y servicios públicos prestados gratuitamente o fuertemente subsi-

\footnotetext{
${ }^{7}$ Los ingresos en especie y los ingresos imputados, como el proveniente de actividades de subsistencia de la familia o alquileres de viviendas ocupadas por los dueños, se excluyen explícitamente o bien se miden de manera tan deficiente que no se tienen en cuenta en la mayoría de las encuestas consideradas en la base de datos, que son encuestas ocupacionales o de ingreso. Solo una minoría de ellas son encuestas de ingresos y gastos, que de alguna manera pueden medir esos rubros (Altimir, 1987).
}

diados y, por lo tanto, los efectos redistributivos de esos gastos públicos. Estas mediciones del ingreso tampoco recogen la influencia de los impuestos indirectos sobre el ingreso real de los hogares.

\section{El método de análisis}

Las advertencias anteriores deben prevenirnos de no confundir el mapa con el territorio. Aunque nuestra preocupación en última instancia sea determinar los cambios en la estratificación social y distinguir entre los que reestructuran permanentemente las sociedades de América Latina y aquéllos relacionados con ajustes transitorios propios de tiempos difíciles, en este caso solo podemos centrar la atención en los cambios agregados en la redistribución relativa del bienestar y en la incidencia de la pobreza, prescindiendo de las variaciones en la composición de los hogares y en sus estrategias económicas, incluida su manera de participar en los mercados laborales.

Además, el análisis se limita a las modificaciones en la distribución del ingreso privado y excluye la distribución del ingreso social (es decir, el que reciben los hogares en forma de bienes o subsidios públicos), para centrarse en los resultados distributivos de la participación de la gente en el proceso productivo y de sus derechos institucionalizados. Este enfoque deja en la penumbra las consecuencias redistributivas inmediatas de las políticas sociales aplicadas mediante el gasto público (no así los resultados del derecho a recibir pagos de la seguridad social), pero capta tanto los efectos de corto plazo de la política económica sobre la distribución del ingreso como las influencias más mediatas y finales de la política pública sobre la estructura del ingreso, que sin embargo aparecen entremezcladas con los cambios estructurales que tienen lugar mucho más allá de la influencia de las políticas.

Con estas limitaciones, he tratado de evaluar aquí el costo redistributivo de la crisis y los ajustes, que es más que el "costo social" a veces medido como las pérdidas del bienestar agregado, pero es mucho menos que el costo social total, si reconocemos que la estructura social es más que la distribución del bienestar y que las condiciones de vida no solo están determinadas por el ingreso.

Evaluar el costo de qué, es otro asunto. Los cambios redistributivos registrados por las mediciones disponibles de la distribución del ingreso incorporan los efectos del ajuste, los cambios institucionales que suponen reformas de las políticas y que son la base de los procesos de reestructuración, así como los efectos 
del ajuste fallido y de la aceleración de la inflación. Sin embargo, puesto que la crisis de los años ochenta es la contraparte de una transformación trascendental del desarrollo de América Latina, las pérdidas distributivas estimadas se atribuyen a aquellos procesos de transformación, marcados en algunos países por períodos de inestabilidad e inflación, políticas fallidas o políticas que suponen un sobreajuste.

El enfoque no se centra en la interacción de las variables macroeconómicas (que se analizó en otros trabajos), ${ }^{8}$ sino en las relaciones entre los cambios en la distribución del ingreso y en la incidencia de la pobreza y los procesos de ajuste, la reforma de políticas y la mutación estructural que están tras los cambios en esas variables macroeconómicas.

Sin embargo, ni la profundidad ni las características de la reestructuración productiva se revelan adecuadamente a través de los cambios en el conjunto de las variables macroeconómicas utilizadas, y solo pueden insinuarse sus consecuencias distributivas permanentes mediante el examen de las situaciones distributivas después de la estabilización y el ajuste.

Por otra parte, la asociación de los cambios distributivos con las reformas de política plantea problemas metodológicos y otros vinculados al horizonte temporal. Las reformas de la política económica orientadas a facilitar o promover el crecimiento sostenible sobre la base de un comercio más liberal y de la inversión privada pueden tener cierta participación en los efectos de corto plazo sobre la distribución del ingreso del conjunto de políticas de estabilización y ajuste junto con las cuales esas reformas se pusieron en práctica. Más aún, algunos de esos efectos pueden haber sido impuestos por la economía política de las reformas para que se arraigaran. A más largo plazo, las reformas pueden tener efectos distributivos negativos en la medida en que se perciba una contraposición entre el crecimiento y la equidad o si esa contraposición pueda preverse sobre la base del modelo de crecimiento promovido por las reformas emprendidas. Para verificar empíricamente en qué medida la reestructuración económica promovida por esas reformas y por las nuevas circunstancias estructurales ha de significar una distribución más desigual del ingreso habrá que aguardar la manifestación a largo plazo de todos sus efectos. Por el momento, solo podemos considerar lo que parecen ser las estructuras distributivas "normales" o más o menos "estables", cuando cada economía retoma una trayectoria de crecimiento sostenido.

\footnotetext{
8 Por ejemplo, véanse Bianchi, Deblin y Ramos (1985 y 1987) y CEPAL (1986).
}

Aun cuando los costos distributivos del ajuste externo, la estabilización, el ajuste fiscal y la reestructuración económica están entremezclados, las características y la secuencia del conjunto de políticas que se aplica ciertamente influyen en la magnitud y duración de las pérdidas distributivas (véase, por ejemplo, García, 1991). Sin embargo, las estimaciones en nuestra base de datos sobre la distribución del ingreso y la pobreza están demasiado espaciadas para derivar de ellas algo más que indicaciones muy generales.

Además, en muchos casos los períodos de análisis impuestos por la disponibilidad de datos incluyen políticas de ajuste o estabilización, seguidas por su fracaso y la aceleración de la inflación, y abarcan por lo tanto los costos distributivos de ambos tipos de procesos.

Los criterios básicos de evaluación que he utilizado en el presente estudio son, por una parte, la comparación entre los cambios distributivos y las modificaciones en las variables macroeconómicas y del mercado laboral durante fases macroeconómicas similares a lo largo del proceso de ajuste en diferentes países y, por otra parte, la comparación de las situaciones distributivas antes y después del ajuste en cada país.

En consecuencia, el análisis se realiza con respecto a diferentes fases de la evolución macroeconómica de cada economía durante los años ochenta, con la hipótesis implícita de que pueden existir diferentes relaciones entre los cambios distributivos y las variaciones macroeconómicas durante períodos de inestabilidad, recesión, recuperación y crecimiento cercano a la frontera de producción. Esta situación, habida cuenta de la escasez de mediciones distributivas para cada país y la falta de uniformidad en cuanto a su correspondencia con fases macroeconómicas similares, nos impide emprender un ejercicio econométrico formal.

En la selección de las variables macroeconómicas se han tenido en cuenta la disponibilidad y la pertinencia analítica. El modelo conceptual implícito relaciona los cambios de desigualdad con los del ingreso nacional real per cápita, ${ }^{9}$ el tipo de cambio real como sustituto de los precios relativos, los gastos de consumo del sector público a precios constantes ${ }^{10}$ como sustituto del empleo

\footnotetext{
${ }^{9}$ Esto es, el producto per cápita después del pago neto de los factores y el efecto de las variaciones de los términos de intercambio; por consiguiente, esta variable incorpora el efecto directo (es decir, contable) de los shocks externos representados por las variaciones de los términos de intercambio y de los intereses devengados sobre la deuda externa.

${ }^{10}$ Es decir, el gasto de consumo público a precios corrientes deflactado por el deflactor del PIB, que es distinto del gasto por consumo público en términos reales según se estima en las cuentas nacionales, que en la práctica latinoamericana refleja, en el mejor de los casos, el empleo del sector público.
} 
y de los salarios reales del gobierno, la inflación, los salarios reales urbanos y la subutilización de la mano de obra urbana (es decir, el desempleo urbano y el empleo informal). Los cambios de la pobreza urbana se relacionan a su vez con las variaciones del ingreso real per cápita, de la desigualdad y del salario mínimo real. Los cambios en la pobreza rural, por otra parte, se relacionan con las variaciones del ingreso real per cápita, el producto agrícola y el tipo de cambio real.

Existen varias limitaciones relacionadas con la medición que impiden establecer una asociación rigurosa entre los cambios observados en la distribución del ingreso y la pobreza y los cambios observados en las variables macroeconómicas. La más importante es que las distribuciones del ingreso observadas, por lo general provenientes de encuestas de hogares sobre mano de obra, miden el ingreso en un mes específico del año, mientras que las mediciones de la mayor parte de las variables macroeconómicas pertinentes se han obtenido en forma anual. Por otra parte, los años respecto de los cuales se dispone de mediciones de la distribución del ingreso o de la pobreza no siempre corresponden a las fases pertinentes de los movimientos coyunturales de la economía (los que, además, en muchos casos han sido numerosos y a menudo en dirección diferente) o a períodos en que determinado conjunto de políticas estaba vigente.

Los análisis de la asociación entre los cambios distributivos y las variables macroeconómicas se centran en la distribución del ingreso y la incidencia de la pobreza en las áreas urbanas, con solo un análisis sucinto de los cambios en la pobreza rural. Hay varias razones para desglosar el análisis. En primer lugar, como se observó anteriormente, las mediciones de la distribución del ingreso y la pobreza a nivel nacional incorporan o mezclan mediciones urbanas y rurales de muy distinta confiabilidad o precisión, lo que hace menos sostenible la hipótesis del "sesgo constante a través del tiempo". Empero, también la mayoría de las variables macroeconómicas tiene una relación diferente con el ingreso urbano o el rural (por ejemplo, el tipo de cambio) o una relación tenue o distante con el ingreso rural (por ejemplo, el desempleo urbano o el empleo informal), o casi ninguna relación con ellos en el corto plazo (por ejemplo, los salarios urbanos); así, el análisis basado en la distribución global del ingreso o la pobreza a nivel nacional vuelve impreciso su valor diferencial explicativo.

Además, respecto de algunos países o períodos solo se dispone de mediciones para las áreas urbanas. Sin duda, esto es un obstáculo para el análisis distributivo. No obstante, su gravedad es menor que en el caso de otras regiones en desarrollo, puesto que en la mayoría de los países de América Latina estudiados más de 60\% de la población es urbana (más de $80 \%$ en los países del Cono Sur y Venezuela) y menos de la mitad de la población es rural (20\% o menos en los países del Cono Sur y Venezuela).

Finalmente, los cambios distributivos de los años ochenta se evalúan asimismo en el ámbito de las tendencias de los años setenta, antes de la crisis, cuando tuvieron lugar diferentes procesos de crecimiento y, en algunos países, se emprendieron reformas de política.

\section{III}

\section{El historial de los años setenta}

\section{La desigualdad}

El análisis de los cambios en la distribución del ingreso y el crecimiento en los principales países de la región durante los años setenta (Altimir, 1992) señala lo siguiente (cuadro 4):

i) Los países cuyo crecimiento durante la décadasufrió agudas perturbaciones, aunque exhibían muy diferentes grados de concentración del ingreso a principios de ella - como Argentina, Chile o Perú- experimentaron considerables aumentos de la desigualdad. ii) Los países que registraron una expansión moderada del producto per cápita (entre $2 \%$ y $3 \%$ ) durante la década, y en los cuales el grado de concentración del ingreso a principios de la misma era intermedio —como Costa Rica y Uruguay—, vieron deteriorarse su situación distributiva.

iii) Tres países (Colombia, México y Venezuela) que registraron ritmos elevados (superiores a $3 \%$ anual) y sostenidos de expansión del producto real per cápita, disminuyeron significativamente sus altos grados de concentración anteriores (coeficientes Gini superiores a 0,5). 


\begin{tabular}{|c|c|c|c|c|}
\hline \multirow[t]{2}{*}{ Países } & \multirow{2}{*}{$\begin{array}{c}\text { Cambios en la concentración } \\
\text { del ingreso }\end{array}$} & \multicolumn{3}{|c|}{ Cambios en la incidencia de la pobreza ${ }^{a}$} \\
\hline & & Nacional & Urbana & Rural \\
\hline \multicolumn{5}{|c|}{ Crecimiento lento $(<1 \%)$} \\
\hline Argentina & I & M & I & $\mathrm{D}$ \\
\hline Chile & I & I & I & I \\
\hline Perú & I & $\mathrm{D}$ & I & D \\
\hline \multicolumn{5}{|c|}{ Crecimiento moderado (2 a 3\%) } \\
\hline Costa Rica & I & $\mathrm{D}$ & M & $\mathrm{D}$ \\
\hline Panamá & $\ldots$ & M & I & $\mathrm{D}$ \\
\hline Uruguay & I & & I & \\
\hline \multicolumn{5}{|c|}{ Crecimiento rápido $(>3 \%)$} \\
\hline Brasil & M & $\mathrm{D}$ & M & $\mathrm{D}$ \\
\hline Colombia & $\mathrm{D}$ & $\mathrm{D}$ & $\mathrm{D}$ & $\mathrm{D}$ \\
\hline México & $\mathrm{D}$ & $\mathrm{D}$ & D & D \\
\hline Venezuela & $\mathrm{D}$ & $\mathrm{D}$ & D & $\mathrm{D}$ \\
\hline
\end{tabular}

Fuente: Altimir (1992).

a I: incremento; M: mantenimiento; D: disminución.

iv) En cambio Brasil, también con una alta y sostenida tasa de expansión (cercana a $6 \%$ anual per cápita) durante los años setenta, no disminuyó su muy elevada concentración establecida en la década anterior (coeficiente Gini de aproximadamente 0,6).

\section{Pobreza}

Los cambios en la incidencia de la pobreza absoluta dependen del crecimiento del ingreso real medio, de los cambios en la distribución del ingreso y también de la postura respecto de la variación de las normas de pobreza a lo largo del tiempo. ${ }^{11}$ Si se utilizan estimaciones comparables de la incidencia de la pobreza en 1970 y alrededor de 1980, tanto con líneas de pobreza constantes como con variación a lo largo del tiempo (Altimir, 1992), destaca lo siguiente para la muestra de países (cuadro 4):

i) Argentina, Chile y Perú, grupo de países con creciente desigualdad y crecimiento bajo e inestable durante el decenio - como consecuencia de perturbaciones económicas y alteraciones institucionales-, tuvieron resultados desalentadores o decididamente

\footnotetext{
${ }^{11}$ A la inversa de la modalidad generalizada de utilizar líneas de pobreza constantes en el tiempo en términos reales, hay un sólido argumento en favor de modificar inclusive las líneas de pobreza absoluta a lo largo del tiempo, en una situación de crecimiento y progreso social (véase Altimir, 1991).
}

desastrosos en materia de pobreza. En Argentina la incidencia de la pobreza a nivel nacional puede haberse incrementado levemente y en Perú inclusive disminuyó, si se aceptan las "conjeturas informadas" respectivas acerca de la disminución de la pobreza rural, pero en ambos países la pobreza urbana tendió a aumentar. En Chile hubo una virtual explosión de la pobreza tanto en las zonas urbanas como en las rurales.

ii) En los dos países que experimentaron un crecimiento moderado con desigualdad creciente (Costa Rica y Uruguay), la incidencia de la pobreza urbana se mantuvo invariable o se incrementó, en tanto que la pobreza rural disminuyó o se mantuvo aproximadamente constante, respectivamente.

iii) Los países que lograron altas tasas de crecimiento per cápita y desigualdad decreciente (Colombia, México y Venezuela) mostraron una reducción significativa de la pobreza absoluta, tanto en las áreas urbanas como rurales. ${ }^{12}$

iv) El intenso crecimiento de Brasil se tradujo en la reducción de la pobreza, aunque no mejorara la distribución relativa del ingreso; sin embargo, si se acepta algún desplazamiento de la línea de pobreza, en reconocimiento de los efectos de ese

\footnotetext{
12 Aun con un desplazamiento de las líneas de pobreza, a causa del elevado crecimiento, la pobreza habría disminuido, aunque en menor grado.
} 
proceso de crecimiento en el estilo de vida prevaleciente, la incidencia de la pobreza en las áreas urbanas se habría mantenido aproximadamente constante.

v) La incidencia de la pobreza en las áreas rurales mostró una tendencia declinante durante los años setenta en casi todos los países estudiados, con independencia del ritmo o estabilidad de su crecimiento, salvo la notoria excepción de Chile.

vi) Las migraciones rurales-urbanas, que fueron especialmente intensas en los años setenta, pueden haber contribuido más que el mejoramiento de las condiciones económicas de las áreas rurales a la reducción absoluta de los pobres rurales en Argentina, Brasil y Venezuela. Por el contrario, el último factor ha influido más que las migraciones para reducir la pobreza rural absoluta en Colombia, México y Panamá y la incidencia de la pobreza rural en Costa Rica y Perú. En Chile, las migraciones rurales-urbanas simplemente amortiguaron el aumento de la incidencia de la pobreza.

\section{IV}

\section{Los años ochenta: reseña de diez países}

La concentración del ingreso y la pobreza aumentaron en las áreas urbanas de casi todos los países de América Latina durante los años ochenta (cuadros 1 y 3). Colombia es la única excepción inequívoca, mientras que México y Costa Rica parecen haber logrado de alguna forma amortiguar el deterioro distributivo causado por los ajustes del decenio y Panamá solo se vio afectada cuando fue perturbada por conflictos políticos e internacionales. Brasil, con un alto grado de desigualdad, también tuvo un deterioro adicional relativamente menor. Chile, Argentina y Uruguay experimentaron graves pérdidas distributivas durante fases diferentes de sus procesos de reforma y ajuste de los últimos dos decenios; su historial de los años ochenta debe considerarse en ese contexto. Perú y Venezuela también experimentaron fuertes pérdidas distributivas como resultado de distintas combinaciones de crisis y políticas fracasadas. Los cambios en la concentración del ingreso ${ }^{13}$ y la pobreza urbana en cada país y período se comparan con los cambios en las variables macroeconómicas y del mercado laboral que se resumen en el cuadro 5.

El caso excepcional es Colombia, donde todos los datos con que se cuenta muestran un mejoramiento

\footnotetext{
${ }^{13}$ Inclusive con mediciones confiables de la distribución del ingreso no se puede captar el ingreso que los residentes del país devengan sobre activos en el extranjero. La fuga de capitales durante los años iniciales de la crisis fue considerable, particularmente en Argentina, México y Venezuela (véase Cumby y Lebich, 1987). Con los rendimientos corrientes en ese entonces, el ingreso por concepto de ventas provenientes de activos acumulados en el extranjero por el sector privado de esos países puede haber representado alrededor de $3 \%$ del ingreso disponible de los hogares en Argentina y México
}

de la distribución del ingreso durante el decenio; entre 1978 y 1988 una reducción relativamente leve de la concentración del ingreso entre los asalariados (Londoño, 1990); entre 1980 y 1986 una disminución significativa de la proporción correspondiente al decil superior de los hogares, principalmente a favor de los estratos medios; además, hasta 1990 ese mejoramiento se profundizó, favoreciendo asimismo los cuatro deciles inferiores de hogares. Sin embargo, la incidencia de la pobreza urbana en 1990 fue aproximadamente similar (alrededor de $35 \%$ ) a las marcas de 1980 y 1986.

Los resultados son generalmente congruentes con las condiciones iniciales antes de la crisis, las tendencias macroeconómicas del período y el estilo tradicionalmente prudente de las políticas económicas colombianas. Cuando estalló la crisis financiera sistémica de los años ochenta, Colombia no tenía un fuerte endeudamiento; el ajuste solo tuvo lugar en 1984-1985 y entonces la política económica indujo gradualmente a reducir al mínimo las pérdidas de salarios y empleos. En realidad, durante el resto del decenio las políticas económicas incluyeron la creación de puestos de trabajo y el mantenimiento de los salarios entre sus objetivos (García, 1991). 
CUADRO 5

América Latina (9 países): Cambios en las variables macroeconómicas y laborales y cambios distributivos en fases diferentes de los años $\mathbf{8 0}$

(Porcentajes de variación en cada periodo)

\begin{tabular}{|c|c|c|c|c|c|c|c|c|c|c|c|c|}
\hline \multirow[b]{2}{*}{ Países } & \multirow[b]{2}{*}{ Períodos } & \multicolumn{3}{|c|}{$\begin{array}{c}\text { Variables } \\
\text { macroeconómicas }^{\mathrm{a}}\end{array}$} & \multicolumn{6}{|c|}{ Mercado laboral $^{\mathrm{b}}$} & \multicolumn{2}{|c|}{$\begin{array}{c}\text { Cambios } \\
\text { distributivos }^{\mathrm{c}}\end{array}$} \\
\hline & & INRpc & TCR & $\mathrm{INF}^{\mathrm{d}}$ & SR & SMR & SENA & EINA & DU & CGpc & $\begin{array}{l}\text { Concentración } \\
\text { (coeficiente } \\
\text { Gini) }\end{array}$ & $\begin{array}{c}\text { Pobreza } \\
\text { urbana }\end{array}$ \\
\hline
\end{tabular}

I. Períodos de ajuste recesivos a shocks externos

\begin{tabular}{|c|c|c|c|c|c|c|c|c|c|c|c|c|}
\hline Argentina & $1980-83$ & -23 & 77 & I & -1 & 37 & 10 & 1 & 81 & -19 & $\mathrm{I} ?$ & $\mathrm{I}+$ ? \\
\hline Brasil & $1979-83$ & -13 & 26 & I & -18 & -5 & 20 & 24 & 8 & -7 & M & I \\
\hline Colombia & $1980-83$ & -5 & -12 & $\mathrm{D}$ & 8 & 7 & 12 & 9 & 21 & 7 & $\mathrm{D}$ & M? \\
\hline Costa Rica & $1980-83$ & -26 & 40 & $\mathrm{I} / \mathrm{D}$ & -18 & -1 & 12 & 12 & 42 & -30 & $\mathrm{I} ?$ & I+ \\
\hline Chile & $1981-83$ & -22 & 34 & I & -11 & -19 & 32 & 5 & 111 & -8 & I & I \\
\hline México & $1981-84^{\mathrm{e}}$ & -12 & 40 & I & -30 & -32 & 12 & 7 & 36 & -14 & $\mathrm{I} ?$ & $\mathrm{I} ?$ \\
\hline Perú & $1982-84$ & -12 & 14 & I & -25 & -20 & 32 & 31 & 35 & -22 & $\ldots$ & I+ \\
\hline Uruguay & $1981-86$ & -19 & 55 & I & -13 & -14 & $\ldots$ & $\ldots$ & 60 & -14 & I & It \\
\hline Venezuela & $1981-86$ & -30 & 51 & - & -19 & 6 & 24 & 6 & 78 & -21 & I & I+ \\
\hline
\end{tabular}

II. Períodos de recuperación después del ajuste externo

\begin{tabular}{|c|c|c|c|c|c|c|c|c|c|c|c|c|}
\hline Argentina & $1983-86$ & - & - & D & 8 & 7 & 10 & 8 & 19 & 24 & I & $\mathrm{I} ?$ \\
\hline Brasil & $1983-87$ & 19 & 13 & $\mathrm{D} / \mathrm{I}$ & 37 & -23 & -11 & -1 & -45 & 42 & I & D \\
\hline Colombia & $1983-86$ & 10 & 67 & I & 4 & 6 & 4 & -2 & 18 & -3 & $\mathrm{D}$ & M \\
\hline Costa Rica & $1983-88$ & 8 & 15 & I & 8 & 16 & -4 & 8 & -25 & 11 & $\mathrm{I} ?$ & $\mathrm{D}$ ? \\
\hline Chile & $1983-87$ & 12 & 72 & - & -3 & -27 & -25 & -16 & -37 & -23 & I & $\ldots$ \\
\hline Panamá & $1982-86$ & 10 & - & & 16 & 13 & $\ldots$ & $\ldots$ & 26 & -3 & $\ldots$ & M? \\
\hline Perú & 1984-87 & 16 & - & $\mathrm{D} / \mathrm{I}$ & 40 & -3 & -15 & -7 & -46 & 28 & $\ldots$ & $\mathrm{D}$ ? \\
\hline Uruguay & 1986-89 & 13 & 12 & $\mathrm{M} / \mathrm{I}$ & 6 & -12 & $\ldots$ & $\ldots$ & -20 & -20 & D & $\mathrm{D}$ \\
\hline Venezuela & 1986-89 & -6 & 52 & I & -38 & -15 & -5 & 4 & -20 & -20 & I & I \\
\hline
\end{tabular}

III. Períodos de recesión a causa de desequilibrios internos

\begin{tabular}{|c|c|c|c|c|c|c|c|c|c|c|c|c|}
\hline Argentina & 1986-89 & -13 & 34 & $\mathrm{I} / \mathrm{H}$ & -19 & -62 & 14 & 8 & 36 & $\ldots$ & I & I+ \\
\hline Brasil & $1987-89$ & -1 & -31 & I & -11 & -1 & -6 & -6 & -11 & 17 & I & I \\
\hline México & $1984-87$ & -8 & 44 & I & -16 & -17 & 21 & 36 & -32 & -20 & $\mathrm{I} ?$ & $\ldots$ \\
\hline Panamá & 1986-89 & -22 & - & $-I$ & -1 & $\ldots$ & $\ldots$ & 61 & -22 & $\mathrm{I}$ ? & I & \\
\hline Perú & $1987-90$ & -30 & -49 & $\mathrm{I} / \mathrm{H}$ & -69 & -64 & $\ldots$ & $\ldots$ & 73 & -58 & $\mathrm{I} ?$ & I \\
\hline
\end{tabular}

IV. Períodos de desinflación y recuperación

$\begin{array}{lllllllllllllll}\text { Argentina } & 1990-91 & 5 & -24 & \mathrm{D} & -7 & 39 & \ldots & \ldots & -13 & \ldots & & \ldots & & \mathrm{D} \\ \text { México } & 1987-89 & 2 & -11 & \mathrm{D} & -2 & -16 & 9 & 14 & -7 & -10 & & \mathrm{I} ? & & \ldots\end{array}$

V. Períodos de crecimiento más allá de la recuperación

\begin{tabular}{|c|c|c|c|c|c|c|c|c|c|c|c|c|}
\hline Colombia & $1986-90$ & 4 & 31 & I & -5 & -5 & -13 & -7 & -25 & 20 & D & D \\
\hline Costa Rica & $1988-90$ & - & -4 & $\mathrm{D} / \mathrm{I}$ & 2 & 5 & -4 & 1 & -14 & 20 & D & I \\
\hline Chile & $1987-90$ & 18 & 5 & I & 11 & 27 & -15 & 1 & -45 & -3 & D & D \\
\hline Venezuela & $1989-90$ & 10 & 4 & D & 1 & -5 & 2 & - & 8 & -9 & D & $\ldots$ \\
\hline
\end{tabular}

Fuente: Cambios en las variables macroeconómicas y laborales: CEPAL y PREALC. Cambios distributivos: cuadros 1 y 3.

a INRpc: ingreso nacional real per cápita; TCR: tipo de cambio efectivo real; INF: inflación.

b SR: salarios reales urbanos o industriales; SMR: salario mínimo real; sENA: subutilización de la fuerza laboral no agrícola (por persona activa) equivalente a EINA+DU; EINA: fuerza laboral no agrícola en actividades informales (definición de prealc); DU: tasa de desempleo urbano; CGpc: gasto de consumo real del gobierno per cápita.

c I: se incrementó; I+: se incrementó mucho; D: disminuyó; m: se mantuvo; “?” indica la suposición más probable para la fase (véase el texto) en el ámbito de los cambios observados en los cuadros 1 y 3 del anexo durante un período más largo.

d I: se incrementó; D: disminuyó; M: la tasa de inflación se mantuvo; H: entró en hiperinflación.

e Este período incluye una recuperación pasajera. 
En 1986 el país acababa de completar un ajuste externo relativamente leve, el ingreso real per cápita era ya $5 \%$ superior al de 1980 y los salarios reales $12 \%$ mayores. Sin embargo, el desempleo urbano era cuatro puntos mayor (es decir, casi 50\% más) que en 1980 y $2 \%$ más de la fuerza de trabajo urbana (es decir, $27 \%$ de ella) se empleaba en actividades informales. El período 1986-1990 fue de crecimiento con cierta estabilidad para la economía colombiana, aunque la situación macroeconómica se deterioró un poco en 1990. El ingreso real per cápita creció más de $4 \%$ durante el período; las exportaciones, los gastos de consumo público y el consumo privado encabezaron la expansión. El desempleo disminuyó consecuentemente (en más de tres puntos) al igual que la importancia del empleo informal, pero los salarios reales aumentaron levemente hasta $1989 \mathrm{y}$ disminuyeron significativamente solo en 1990.

En México las mediciones existentes muestran una disminución considerable de la desigualdad, junto con una reducción de la pobreza a nivel nacional entre 1977 y 1984 y el deterioro consiguiente entre 1984 y 1989 , período durante el cual cambió radicalmente la posición del gobierno en materia de políticas (Lustig, 1992). La observación de 1984 se ubica en medio del primer programa de ajuste y estabilización, en momentos en que tenía lugar una moderada recuperación económica después del ajuste recesivo (Lustig, 1992). Sin embargo, los salarios reales habían bajado casi $30 \%$ en dos años y los gastos de consumo público per cápita habían disminuido $14 \%$. Es probable que el mejoramiento de la concentración en relación con 1977, más allá de la posibilidad siempre presente de que las dos mediciones no sean comparables, oculte un deterioro respecto de una situación distributiva considerablemente mejor alcanzada durante el período de crecimiento vigoroso (6\% anual) anterior a la crisis, particularmente en las áreas urbanas.

Sea como fuere, hay pruebas indicadoras de una mayor desigualdad entre 1984 y 1989, cuando la economía mexicana se recuperaba a un ritmo de crecimiento moderado con inflación controlada, después de haber absorbido los efectos de la crisis del petróleo (el ingreso nacional real per cápita aún era $7 \%$ menor que en 1984) y en un período en que la disciplina fiscal y las reformas de las políticas avanzaban progresivamente. Durante ese lapso, los gastos de consumo público per cápita se redujeron más de $30 \%$ en términos reales y los salarios reales urbanos disminuyeron un $26 \%$ adicional. Al mismo tiempo, el desempleo descendió a niveles inferiores a los observados durante la bonanza del petróleo y el empleo informal aumentó diez puntos a más de $30 \%$ de la mano de obra no agrícola. Ambos hechos, concordantes con la notable flexibilidad de los salarios reales, deben haber amortiguado el impacto sobre el ingreso de los hogares pobres y de estratos populares (Lustig, 1992).

Costa Rica se ha caracterizado tradicionalmente por su estabilidad política y económica y el ajuste de su economía durante los años ochenta recibió la ayuda importante de transferencias oficiales procedentes de los Estados Unidos. Sin embargo, la distribución del ingreso urbano empeoró entre el comienzo y el final del decenio, aunque el mejoramiento del ingreso rural puede haber contribuido a mantener la concentración anterior del ingreso a nivel nacional. ${ }^{14} \mathrm{El}$ deterioro que se produjo entre 1981 y 1988 solo se invirtió parcialmente durante el bienio posterior y ello favoreció a los estratos de clase media más que a los pobres. En consecuencia, la pobreza urbana aumentó notoriamente entre 1981 y 1988 y avanzó un poco más hasta 1990.

Hay evidencia de que durante el ajuste recesivo externo de 1981-1982 el empobrecimiento se agudizó, mientras que la posterior estabilización y recuperación en 1983-1986 produjo una disminución de la pobreza absoluta a niveles de incidencia cercanos a los que existían antes de la crisis (Trejos, 1991). Al menos esto es lo que al parecer sucedió a nivel nacional; la devaluación real puede haber incrementado el ingreso de los pobres rurales, como sostienen Morley y Álvarez (1992), y el aumento real, después del ajuste, de los salarios en las actividades formales puede haber mejorado la situación de los estratos medios bajos. Por otra parte, el deterioro del ingreso real en las actividades informales, que se habían ampliado, puede haber incrementado el número de pobres urbanos. ${ }^{15}$

En el período posterior, marcado por las reformas de las políticas (especialmente la liberalización comercial) y la expansión inestable, los datos de que se dispone señalan una estabilización relativa de la incidencia de la pobreza a nivel nacional (Trejos, 1991; CEPAL, 1992a), pero también, como ya se indicó, una tendencia al aumento de la pobreza urbana, en el marco de una reducción del salario real, la baja gradual del ingreso real per cápita y una estabilidad relativa del tipo de cambio. Por otra

\footnotetext{
${ }^{14}$ Morley y Álvarez (1992, cuadros 7b y 7c) sostienen que la devaluación real que fue preciso efectuar para el ajuste externo supuestamente incrementó los salarios agrícolas después de 1981, aunque la mayor parte de la devaluación se produjo ese año. También comprueban que entre 1981 y 1989 el ingreso nominal rural en los deciles inferiores de la distribución nacional aumentó más que el de los hogares urbanos en los mismos deciles.

${ }^{15}$ Según Morley y Álvarez (1992, cuadro 7h), hubo un brusco deterioro de los salarios nominales en los servicios no básicos en relación con la industria en los hogares urbanos, entre 1981 y 1986.
} 
parte, el aumento de los gastos de consumo público en términos reales ( $20 \%$ per cápita) debe haber contribuido al mejoramiento observado en la posición relativa de los grupos de ingreso medio.

Los shocks externos que encendieron la crisis en otros países latinoamericanos tuvieron un impacto desfasado y atenuado en la economía de Panamá, que solo sufrió un breve estancamiento de la actividad económica en 1983-1984. A pesar del incremento de $23 \%$ del ingreso real per cápita y un aumento de $14 \%$ de los salarios reales, entre 1979 y 1986 la pobreza urbana solo disminuyó levemente, a menos de $30 \%$ de los hogares. La crisis política combinada con el conflicto internacional que llevó a la economía panameña a la recesión en 1988-1989, hizo caer el ingreso real per cápita a $5 \%$ por debajo del nivel de 1979 (aunque esto no sucedió con los salarios reales), redujo los gastos de consumo público per cápita en más de $20 \%$ e incrementó 10 puntos porcentuales el desempleo abierto de la mano de obra urbana. Con esto se incrementó significativamente la concentración del ingreso, al igual que la pobreza, que afectó al 34\% de los hogares urbanos.

La distribución sumamente desigual del ingreso que ya existía en Brasil, y que no había mejorado durante el decenio anterior de elevado crecimiento, empeoró más aún en los años ochenta. La desigualdad de la distribución del ingreso de los hogares se mantuvo relativamente estable durante la recesión de 1981-1983 y la recuperación posterior, y mejoró leve y brevemente en 1986 en el marco del crecimiento y la estabilidad temporal creados por el Plan Cruzado. Por el contrario, entre ese año y 1989, al acelerarse la inflación y comenzar la recesión actual, la concentración del ingreso se incrementó. Sin embargo, hay datos (Hoffman, 1992) que indican que la desigualdad del ingreso de los hogares mejoró un tanto en 1990.

En consecuencia, la distribución del ingreso en 1989 estaba más concentrada que en 1979 y la pobreza afectaba a 5\% más de los hogares urbanos, mientras el ingreso nacional real per cápita y los salarios industriales se hallaban casi al mismo nivel que al final del decenio anterior; pero el desempleo había aumentado más de 3\%, al igual que el empleo informal. Por otra parte, el aumento de los gastos de consumo público (55\% per cápita entre 1979 y 1989) debe haber contribuido a amortiguar el deterioro relativo de los grupos de medianos ingresos. La caída de la actividad económica y del ingreso en 1990, junto a una reducción real de $20 \%$ de los salarios industriales, aumentó la pobreza urbana otro $4 \%$ hasta alcanzar casi $39 \%$ de los hogares.
Los shocks externos y las reformas de política bajo el régimen autoritario de Pinochet, junto con la consiguiente inestabilidad y un bajo crecimiento medio, provocaron cambios importantes en la distribución del ingreso y la pobreza en Chile durante los años setenta y ochenta. La distribución del ingreso experimentó un deterioro significativo; no solo se revirtió la efímera redistribución que duró hasta 1974 sino que el patrón distributivo en la sociedad chilena sufrió una metamorfosis.

En 1980, después de la recuperación de la profunda depresión (el PIB per cápita era solo 6\% superior al de 1970), la puesta en práctica de un programa radical de liberalización comercial, la reversión de la reforma agraria y la implantación de reformas institucionales permitieron una mayor flexibilidad del mercado laboral, pero también dieron lugar a la represión laboral (Ffrench-Davis y Raczynski, 1987), el decil superior de los hogares percibía al menos cinco puntos más del ingreso total que en 1968, en detrimento de la participación —e ingreso real- de los estratos medios y bajos. Los salarios reales aún eran $10 \%$ menores que en 1970, 17\% de la fuerza laboral estaba sin empleo y $28 \%$ se dedicaba a actividades informales. La pobreza absoluta estalló virtualmente en las áreas urbanas, donde pasó de 12\% en 1970 a cerca de $28 \%$ en 1980 , y en las áreas rurales, lo que llevó la incidencia de la pobreza a nivel nacional a cerca de $30 \%$ de los hogares (Altimir, 1991).

Durante la crisis de 1982-1983 se agravó más la desigualdad existente, aunque quizá de manera marginal respecto del vuelco del período anterior, y la pobreza urbana se incrementó aún más. ${ }^{16} \mathrm{El}$ deterioro puede haber continuado hasta 1987, cuando el ingreso real per cápita y los salarios reales todavía eran respectivamente $12 \%$ y $5 \%$ menores que en 1980 , los gastos de consumo público per cápita se habían reducido más de $30 \%$ y el desempleo todavía afectaba a $17 \%$ de la fuerza de trabajo, aun cuando había disminuido la proporción de las actividades informales. En esas circunstancias, la pobreza urbana se había elevado cerca de cuatro puntos (14\% calculada sobre una base per cápita) y la distribución del ingreso se había concentrado más aún en favor del quintil superior, cuya proporción de los gastos se incrementó en casi $4 \%$ del total respecto de 1978 , en detrimento de los estratos medianos y bajos; estos últimos sufrieron una mayor pérdida relativa.

Solamente entre 1987 y 1990, cuando la economía chilena alcanzó plena utilización de la capacidad productiva y con las reformas progresivas de las leyes

\footnotetext{
${ }^{16}$ Pollack y Uthoff (1987) estiman un incremento de ocho puntos porcentuales (de $40 \%$ a $48 \%$ ) de la pobreza absoluta en el Gran Santiago.
} 
laborales, mejoró un tanto el panorama distributivo. El ingreso real per cápita aumentó $18 \%$, los salarios reales $11 \%$ y el desempleo se redujo en casi seis puntos hasta cerca de $7 \%$ de la fuerza laboral. No obstante estos resultados, la concentración del ingreso urbano solo disminuyó levemente en favor de los grupos de menores ingresos y la pobreza urbana se redujo en dos puntos; la pobreza rural disminuyó más significativamente, lo que llevó la incidencia de la pobreza a nivel nacional a menos de $35 \%$ de los hogares.

En Argentina han tenido lugar asimismo cambios distributivos importantes desde los años setenta, en períodos sucesivos de inestabilidad económica y desorganización política. Después del advenimiento del régimen militar en 1976 se llevaron a cabo reformas de política para liberalizar los precios, el comercio y el mercado financiero, pero no el empleo y los salarios (que estuvieron bajo control durante la mayor parte del período). La actividad económica se caracterizó por su intermitencia en el ámbito de un régimen de alta inflación, a pesar de la decisiva postura antiinflacionaria que se adoptó en materia de política económica y que fue un elemento dominante en tres programas sucesivos (Canitrot, 1981).

Entre 1970 y 1980 la concentración del ingreso aumentó considerablemente: el decil superior de hogares incrementó su participación en el ingreso total en casi cinco puntos, mientras los estratos más bajos perdieron casi tres puntos. La pobreza urbana aumentó dos puntos hasta 7\%. La mayor parte de ese deterioro, sin embargo, tuvo lugar después de $1974 .{ }^{17}$ En 1980 el ingreso real per cápita era aproximadamente similar y los salarios reales en las manufacturas todavía eran $14 \%$ inferiores a los de 1974, mientras el desempleo era muy bajo.

Las grandes fluctuaciones de la actividad económica, la magnitud de los shocks externos y de los consiguientes ajustes, así como las oscilaciones de los precios relativos, asociadas con una inflación alta y acelerada durante los años ochenta, se acompañaron de movimientos en la distribución relativa del ingreso, aunque quizá no tan intensos como el flujo y reflujo macroeconómico (Beccaria, 1991). En 1986 había aumentado más la concentración del ingreso respecto de 1980, lo que suponía un cambio espectacular a partir del comienzo de los años setenta: la participación del decil superior en el ingreso había aumentado casi tanto como en el decenio anterior, pero esta vez a expensas principalmente de los estratos de nivel medio. La pobreza urbana había subido seis

\footnotetext{
${ }^{17}$ Véase en Altimir (1986) la evolución de la distribución del ingreso, y en Beccaria y Minujin (1991) la evolución de la pobreza absoluta durante el período.
}

puntos (es decir, casi se duplicó) y afectaba a más de $12 \%$ de los hogares. Aunque la economía se recuperaba en virtud de un acertado programa de estabilización, el ingreso real per cápita era aún $22 \%$ inferior al nivel de 1980, el desempleo se situaba tres puntos más arriba y el empleo informal dos puntos más arriba; por otra parte, el salario real era $6 \%$ superior que al comienzo del decenio.

Después de 1986, la aceleración inflacionaria y la baja de los salarios reales fueron a la par con un mayor deterioro de la distribución relativa del ingreso, que culminó en 1989; cuando estalló la hiperinflación y la recesión alcanzó el punto más hondo, la concentración llegó al nivel máximo. En 1990 la concentración del ingreso entre los receptores individuales retrocedió a los niveles ya elevados que alcanzó en 1988 (Beccaria, 1991). Entre 1986 y 1990 la pobreza puede haber abarcado un $6 \%$ adicional de los hogares urbanos (aumento de más de $50 \%$ sobre una base per cápita) y solo mejoró en 1991, cuando los precios se estabilizaron y comenzó la recuperación económica.

Uruguay es otro país del Cono Sur que había emprendido reformas de política en los años setenta, bajo un régimen autoritario, con importantes consecuencias distributivas. A partir de 1974 se liberalizó el mercado financiero y se eliminaron gradualmente los controles de precios, mientras los salarios siguieron siendo administrados; a partir de 1979 entró en vigor un programa de liberalización comercial. El período 1973-1981 fue de crecimiento económico relativamente alto $(3,4 \%$ per cápita al año); sin embargo, la distribución del ingreso se deterioró abruptamente entre 1973 y 1979, a expensas de los estratos medianos y bajos, y mejoró algo posteriormente, solo para beneficio de los estratos de ingresos medios. Esa evolución siguió muy de cerca la relación entre el ingreso nacional real per cápita y los salarios reales: el primero aumentó $12 \%$ entre 1973 y 1979, mientras que estos últimos bajaron $32 \%$; entre 1979 y 1981 el ingreso real se incrementó $4 \%$, pero los salarios reales crecieron cerca de $17 \%$. Por otra parte, la pobreza urbana aumentó en cuatro puntos porcentuales (40\% sobre una base per cápita) entre 1970 y 1981.

Los shocks externos y los ajustes consiguientes redujeron radicalmente el ingreso per cápita en $19 \%$ entre 1981 y 1986; el salario real descendió $8 \%$ y el desempleo aumentó cuatro puntos, mientras los gastos de consumo público per cápita se redujeron en más de $30 \%$. La concentración del ingreso aumentó nuevamente y la pobreza urbana creció otros cinco puntos porcentuales, al $14 \%$ de los hogares. Como resultado de la recuperación económica y la ulterior estanflación, el ingreso real per 
cápita en 1989 fue $13 \%$ superior al de 1986 y los salarios reales $6 \%$ mayores, mientras el desempleo había disminuido dos puntos porcentuales. Por consiguiente, mejoró la distribución del ingreso urbano y se redujo la pobreza urbana en cuatro puntos porcentuales. De modo que al final del decenio la distribución relativa del ingreso y la incidencia de la pobreza absoluta eran aproximadamente similares a las del comienzo, en tanto que los salarios reales eran considerablemente menores y el desempleo algo mayor que en 1981.

El constante deterioro del ingreso nacional real en Venezuela entre 1980 y 1986, provocado por la caída de los ingresos del petróleo y la consiguiente reducción (alrededor de 20\%) de los salarios reales y los gastos de consumo público per cápita se acompañó de un fuerte empeoramiento de la situación distributiva. Entre 1981 y 1986 la pobreza urbana aumentó siete puntos porcentuales (casi $40 \%$ sobre una base per cápita) mientras se acentuó también la desigualdad en la distribución relativa del ingreso.

La política económica no logró ajustarse a la caída de los precios del petróleo en 1986; aumentaron los desequilibrios externos y fiscales y se triplicó la tasa de inflación. El programa ortodoxo de estabilización puesto en marcha a principios de 1989, junto con las primeras medidas de liberalización de los precios y el comercio de un programa de reformas de política, causaron una recesión y bajas pronunciadas de los gastos de consumo público y de los salarios reales, mientras que quedaron anulados los avances logrados anteriormente en materia de empleo y se expandieron las actividades informales. Por consiguiente, aumentó la pobreza ${ }^{18}$ y la distribución del ingreso aparentemente se "igualó hacia abajo". El aumento de los ingresos del petróleo por el conflicto del Golfo Pérsico en 1990, y el consiguiente gasto público en 1991, alimentaron una expansión extraordinaria e insostenible de la actividad económica. Ello, sin embargo, fue principalmente en beneficio de los estratos medios altos; la pobreza urbana en 1990 aún era nueve puntos porcentuales mayor que en 1986 y 16 puntos mayor (es decir, casi el doble) que la de 1981. Por otra parte, hay datos que indican que en 1991 la pobreza quizá haya disminuido un tanto, al menos a nivel nacional. ${ }^{19}$

El empeoramiento de la distribución del ingreso en las áreas urbanas de Perú en los años setenta se agravó durante la crisis y ajuste externo de 1982-1985, en un clima de violencia cada vez mayor. A fines de 1985 y comienzos de 1986, cuando la economía se recuperaba bajo el impulso de un programa de estabilización heterodoxo e insostenible puesto en práctica por el gobierno recién elegido de García, el ingreso nacional real per cápita y los salarios reales en el sector privado todavía eran $9 \%$ y $5 \%$ menores que en 1979 , en tanto que un $10 \%$ adicional de la fuerza de trabajo no agrícola estaba empleada en actividades informales (alcanzando a más de $40 \%$ ). En ese entonces, la pobreza urbana aún afectaba a $45 \%$ de los hogares urbanos, 10 puntos porcentuales más que en 1979.

Aunque no existen observaciones comparables para los años subsiguientes, hay algunos datos que indican que en 1990, en medio de la hiperinflación y el colapso económico, la pobreza puede haber aumentado más de $50 \%$ con respecto a 1985-1986, y que empeoró aún más en 1991, cuando el gobierno de Fujimori puso en ejecución el actual programa de estabilización. ${ }^{20}$

\footnotetext{
${ }^{18}$ Márquez (1992) estima que la pobreza, a nivel nacional, afectaba a $28 \%$ de los hogares en 1985, 32\% en 1987 y $41 \%$ en 1989.

${ }^{19}$ Según Márquez (1992), la pobreza a nivel nacional en ese año abarcó $35 \%$ de los hogares, en comparación con $41 \%$ en 1989, momento en que fue sin duda mayor que en 1990.

${ }^{20}$ Véase Figueroa (1992, cuadro 2) y Abugattas y Lee (1991, cuadro 4).

Por otra parte, la comparación de las distribuciones del ingreso de los
}

hogares de Lima según la magnitud de los gastos de consumo per cápita, a partir de los estudios de medición de los niveles de vida de 1985-1986 y 1990 (Psacharopoulos y otros, 1992), revela un escaso incremento de la desigualdad entre las dos observaciones; ello puede reflejar otro caso de "igualación hacia abajo" por recesión, en el cual el consumo real de los pobres descendió casi $7 \%$ al año y el consumo real del decil más rico casi $6 \%$ al año. 


\section{$\mathrm{V}$}

\section{La pobreza rural}

En la mayoría de los países de nuestra muestra se observa una disminución, aunque leve en algunos casos, de la incidencia de la pobreza rural en los años ochenta, con lo que de algún modo se continúa, al menos por inercia, la tendencia a la disminución de la pobreza rural que se manifestó en el decenio anterior. Las únicas excepciones claras son Panamá y Venezuela, donde la tendencia parece haberse invertido al final del decenio, y posiblemente Argentina, país para el cual se ha estimado un leve aumento de la pobreza rural. Chile es un caso especial: en este país el empobrecimiento rural de los años setenta continuó hasta bien entrado el decenio siguiente, pero se revirtió en los últimos años (cuadro 3).
Esos incrementos excepcionales se asocian con la caída del ingreso real per cápita, pero lo contrario no es cierto: de los nueve intervalos registrados de reducción de pobreza rural, solamente en cuatro ${ }^{21}$ aumentó el ingreso real per cápita; en los cinco restantes la pobreza rural disminuyó a la vez que bajaba el ingreso nacional real. Por el contrario, existe una estrecha asociación entre una menor pobreza rural y el aumento de la producción agrícola, que se confirma en ocho de los nueve casos, lo que indica que los campesinos de alguna manera participan de la prosperidad rural general. Sin embargo, en contra de la opinión aceptada, el nexo con la devaluación real del tipo de cambio es menos estrecho, ${ }^{22}$ puesto que se

CUADRO 6

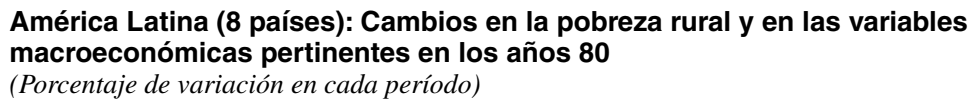

\begin{tabular}{|c|c|c|c|c|c|}
\hline \multirow[t]{2}{*}{ Países } & \multirow[t]{2}{*}{ Períodos } & \multirow{2}{*}{$\begin{array}{c}\text { Cambios en } \\
\text { la pobreza rural } \\
\text { (porcentaje) }^{\mathrm{a}}\end{array}$} & \multicolumn{3}{|c|}{$\begin{array}{c}\text { Cambios en las variables macroeconómicas } \\
\text { (porcentajes) }\end{array}$} \\
\hline & & & $\begin{array}{l}\text { Ingreso nacional real } \\
\text { per cápita }\end{array}$ & PIB agrícola & Tipo de cambio real \\
\hline Argentina & $1980-1986$ & 4 & -23 & 12 & 75 \\
\hline \multirow{2}{*}{ Brasil } & $1979-1987$ & -3 & 4 & 41 & 43 \\
\hline & $1987-1990$ & -6 & -7 & - & -38 \\
\hline Colombia & $1980-1986$ & -7 & 5 & 11 & 47 \\
\hline \multirow[t]{2}{*}{ Costa Rica } & 1981-1988 & -3 & -5 & 18 & -6 \\
\hline & $1988-1990$ & -10 & - & 10 & -4 \\
\hline \multirow[t]{2}{*}{ Chile } & $1980-1987$ & 11 & -13 & 33 & 89 \\
\hline & $1987-1990$ & -19 & 18 & 14 & 5 \\
\hline \multirow[t]{2}{*}{ Panamá } & 1979-1986 & -4 & 23 & 11 & - \\
\hline & 1986-1989 & 11 & -22 & 7 & - \\
\hline Perú & $\begin{array}{l}1979- \\
1985 / 1986\end{array}$ & -2 & -9 & 12 & -9 \\
\hline \multirow[t]{2}{*}{ Venezuela } & 1981-1986 & -3 & -30 & 23 & 51 \\
\hline & $1986-1990$ & 12 & $3^{b}$ & 1 & 59 \\
\hline
\end{tabular}

Fuente: CEPAL.

a Tomado de las estimaciones del cuadro 3.

b 1986-1989: -6\%.

${ }^{21}$ Brasil (1979-1987), Colombia (1980-1986), Chile (1987-1990) y Panamá (1979-1986).

${ }^{22} \mathrm{Al}$ menos sin admitir desfases temporales entre la devaluación real, la reasignación de recursos a los bienes transables, la expansión resultante de la producción agrícola y la consiguiente participación de campesinos y obreros en esa expansión. 
observa solamente en cuatro de los casos, y en la mayor parte de ellos con bajos parámetros (cuadro 6).

Todo esto indica que, a falta de una reforma institucional profunda, ${ }^{23}$ los cambios estructurales de lenta evolución en el medio rural afectan al proceso de reducción de la pobreza rural más que los cambios a corto e incluso mediano plazo en las variables macroeconómicas, aunque estas pueden disminuir el ritmo de ese proceso o aun invertirlo temporalmente.

Esos cambios de lenta evolución se reflejan en parte en la transferencia constante de la pobreza rural a las áreas urbanas a través de las migraciones. En los años ochenta, estas fueron menos intensas que en el decenio anterior, pero de todos modos considerables. En la mayoría de los países las migraciones del campo a la ciudad constituyeron la fuerza de sustento principal de la tendencia hacia la reducción de la pobreza en las áreas rurales, aunque quizá no hayan sido suficientes, como lo fueron en los años setenta, para impedir el aumento absoluto de los pobres rurales.

\section{VI}

\section{Cambios transitorios y permanentes en la distribución del ingreso}

Con el fin de esclarecer en alguna medida si los cambios en la desigualdad producidos en la década de crisis y ajustes pueden ser permanentes, y hasta qué punto, es vital considerar las diferentes fases macroeconómicas por las que han atravesado los países de América Latina y cuáles son las condiciones estructurales en que cada uno de ellos se halla actualmente, así como la índole y profundidad de las reformas de política emprendidas. En el cuadro 5 se resumen los cambios de las variables macroeconómicas y laborales y los cambios distributivos en períodos seleccionados que corresponden a distintas fases macroeconómicas de los años ochenta. ${ }^{24}$

\section{Distribución del ingreso y la pobreza en las distintas fases de los procesos de ajuste}

El ajuste recesivo ante los shocks externos a comienzos del decenio ha tenido efectos adversos sobre la desigualdad y efectos devastadores sobre la pobreza urbana en toda América Latina. No cabe duda de que la concentración del ingreso aumentó en Argentina, Chile, Uruguay y Venezuela y quizá también en Costa Rica y México, mientras que en Brasil la desigualdad aparentemente se mantuvo invariable a través del rápido ajuste de 1981-1984 (Hoffman, 1992). En todos estos casos, la

${ }^{23}$ Como la reforma agraria en Perú o la marcha atrás de esta en Chile, ambas en los años setenta.

${ }^{24}$ Los intervalos entre mediciones de la pobreza (cuadro 3) o de la distribución del ingreso (cuadro 1) suelen abarcar más de una fase de la evolución económica; en esos casos, los cambios distributivos indicados en el cuadro se basan también en la evidencia mencionada en el texto. pobreza urbana aumentó durante el ajuste, junto con la subutilización de la fuerza de trabajo urbana ${ }^{25}$ (que se incrementó entre $10 \%$ y $20 \%$, según el país); asimismo, hubo bajas considerables del ingreso real per cápita, de los salarios reales medios ${ }^{26} \mathrm{y}$ de los gastos reales de consumo público per cápita.

Colombia destaca como excepción, debido en parte a la menor carga inicial de su deuda. La economía pasó por un ajuste externo, aun con una valorización real de la moneda, y por una reducción sin sobresaltos del ritmo inflacionario, lo que permitió aumentos reales en los sueldos y salarios mínimos e inclusive la expansión real de los gastos de consumo público per cápita. Tal era el telón de fondo para un mejoramiento probable de la distribución del ingreso y el no agravamiento de la pobreza absoluta. Aunque Panamá pasó también por un ajuste leve en 1982-1984, con aumento de los salarios reales pero con un mayor desempleo, en este caso no tenemos ningún indicio de los cambios distributivos en ese período.

\footnotetext{
${ }^{25} \mathrm{El}$ indicador de subutilización de la fuerza de trabajo urbana usado en este caso es la suma de la tasa de desempleo abierto (urbano) y la proporción de la fuerza de trabajo no agrícola en las actividades informales, estimada por PREALC.

${ }^{26}$ En Argentina, sin embargo, los salarios reales se recuperaron y el salario mínimo dio un salto en 1983, al final del régimen militar en desintegración, pese a la aceleración de la inflación. En Chile el salario real medio (en las actividades formales) aumentó hasta 1982, en el marco de una inflación moderada, una alta subutilización de la mano de obra (casi la mitad de la fuerza laboral no agrícola) y un nuevo régimen laboral que concedió flexibilidad total al mercado laboral (García, 1991).
} 
La recuperación después del ajuste externo solo en algunos países trajo alivio en el frente de la pobreza. En Brasil ello puede asociarse al incremento acumulativo del ingreso real per cápita (cerca de 20\%) y los salarios reales $(37 \%)$ y a una merma de la subutilización de la mano de obra, a pesar de un probable incremento de la desigualdad. ${ }^{27}$ Si Perú experimentó también una disminución de la pobreza urbana durante esta fase - lo que no se sabe con certeza, pero es verosímilpuede haberse debido a una configuración similar de cambios en el nivel de actividad y el mercado laboral. La disminución de la pobreza en Uruguay — junto con la desigualdad - y quizá en Costa Rica y Panamá, y el mantenimiento posible de su ya reducida incidencia en Colombia, también se asocian con cambios en el ingreso y las variables laborales, en el mismo sentido aunque de magnitud menos espectacular. ${ }^{28}$

Por el contrario, la recuperación en Argentina, Chile y Venezuela se acompañó de nuevos aumentos de la pobreza urbana, aunque por distintas razones. En Argentina una recuperación vacilante y solo parcial, y el incremento del desempleo y la mano de obra informal, aparentemente pesaron más que el alza moderada de los salarios reales y la reducción temporal de la inflación. Asimismo en Venezuela, hasta 1989, la recuperación había sido parcial y sujeta a shocks externos adversos, con aceleración de la inflación; por otra parte, la reducción $(-38 \%)$ de los salarios reales y de los gastos de consumo per cápita (-20\%, en términos reales) predominó sobre una disminución muy limitada de la subutilización de la mano de obra; tal fue el escenario en que tuvieron lugar los aumentos de la desigualdad y la pobreza urbana. En el caso de Chile la total flexibilidad del mercado laboral dio lugar a un deterioro de la equidad a mediano plazo; la recuperación de 1983-1987 fue vigorosa y la subutilización de la mano de obra disminuyó significativamente, aunque todavía se situó por encima de la tercera parte de la fuerza laboral urbana; pero los salarios reales y los gastos de consumo público per cápita se mantuvieron a duras penas, en una situación de inflación moderada y más o menos constante. Tanto la desigualdad como la pobreza absoluta aumentaron.

En los países que de nuevo se hundieron en la recesión después de recuperarse del ajuste externo, debido

\footnotetext{
27 Sin embargo, el incremento conspicuo de los gastos reales de consumo público per cápita (42\%) debe haber mejorado la posición relativa de algunos estratos de ingresos medios.

${ }^{28}$ La breve y leve recuperación de México en 1984 no modificó significativamente los resultados de la anterior fase recesiva, aunque "las mismas circunstancias que [la] desencadenaron contribuyeron en parte a su extinción" junto con un empeoramiento de los términos de intercambio en 1985 (Lustig, 1992, pp. 34-36).
}

a desequilibrios internos generalizados, shocks externos adicionales y la aceleración de la inflación combinada con esfuerzos de estabilización, los aumentos de la desigualdad y la pobreza absoluta fueron aún mayores.

En Argentina y Perú esos desequilibrios condujeron la economía a la hiperinflación y en Brasil la llevaron al borde de ella; los ingresos y salarios reales cayeron en picada y aumentó la subutilización de la fuerza laboral, al igual que la pobreza absoluta y la desigualdad del ingreso. La superación de la hiperinflación en Argentina en 1990 detuvo la caída e inclusive trajo cierto mejoramiento marginal de la desigualdad, aunque no impidió un mayor incremento de la pobreza. La aceleración del ritmo inflacionario en Brasil tuvo lugar junto con cierta expansión económica y más aumentos en los gastos de consumo público per cápita, aunque con un estancamiento del ingreso real per cápita y la declinación de los salarios reales; sin embargo, el programa de medidas de estabilización de 1990 provocó desinflación con recesión, lo que aparentemente aumentó más aún la pobreza.

Los shocks externos en 1985-1986 y los esfuerzos de estabilización determinaron también en México un nuevo período recesivo; el aumento de la informalidad y la caída de los salarios reales sugieren un mayor incremento de la pobreza urbana y, asimismo, junto con el descenso de los gastos de consumo público per cápita, que parte del incremento observado de la desigualdad hasta 1989, puede haber tenido lugar durante este período. En Panamá la profunda recesión de 1988-1989, desencadenada por conflictos políticos e internacionales, aumentó la pobreza urbana y posiblemente también la desigualdad.

Los dos casos de estabilización y recuperación después de una alta inflación y recesión a finales de los años ochenta (Argentina en 1990-1991 y México en 1987-1989) mostraron incrementos moderados del ingreso real y de la utilización de la mano de obra urbana y también reducciones moderadas de los salarios reales. En Argentina disminuyó la pobreza urbana desde los altos niveles de incidencia alcanzados durante los períodos anteriores. En el caso de México no hay pruebas que indiquen una reducción similar de la pobreza o una disminución de la desigualdad.

En casi todos los pocos casos observados de crecimiento sostenido o aun insostenible después de la recuperación, tales circunstancias trajeron consigo un mejoramiento de la distribución relativa del ingreso y cierta disminución de la pobreza urbana. Solamente en Costa Rica en 1990 aumentó la pobreza urbana, con la aceleración de la inflación y particularmente con la eliminación de los subsidios y el alza de las tarifas de los 
servicios públicos. En Colombia y Chile disminuyeron la desigualdad y la pobreza; en este último caso, los aumentos del ingreso y los salarios reales fueron más marcados, pero en Colombia aumentaron los gastos reales de consumo público per cápita. En Venezuela hay indicios de una menor concentración del ingreso en 1989-1990, a pesar del descenso de los salarios reales y un mayor desempleo.

\section{Cambios permanentes en la concentración del ingreso}

Examinemos primeramente los países que ya han alcanzado una etapa de crecimiento a plena capacidad. Colombia es el único en que la concentración del ingreso en dicha etapa es menor que antes de la crisis. Por otra parte, en Costa Rica en 1990 la desigualdad urbana fue solo levemente mayor que en 1981. En ambos países el salario real y los gastos de consumo público per cápita fueron mayores que al comienzo del decenio (cuadro 7).

Por el contrario, en Chile, después de que se retomara la trayectoria de crecimiento a mediano plazo, la estructura del ingreso está significativamente más concentrada que antes de la crisis y ciertamente mucho más que la distribución relativa del ingreso prevaleciente a finales de los años sesenta, antes del experimento socialista-populista y las reformas estructurales autoritarias de los años setenta (cuadro 1). Ello a pesar de un salario real casi recuperado. Asimismo, en Venezuela la concentración del ingreso es mayor que antes de la crisis, después de que la recuperación evolucionó hacia un crecimiento rápido pero insostenible; en este caso, tanto los salarios reales como los gastos de consumo público per cápita son significativamente menores que antes de la crisis.

México y Uruguay, aunque en 1989 todavía no se hallaban en una trayectoria de crecimiento a plena capacidad, se aproximaban a la culminación de sus recuperaciones respectivas; en dicha etapa la desigualdad del ingreso casi había vuelto en ambos casos a los niveles anteriores a la recesión. ${ }^{29}$ En México ello ocurrió a pesar de la radical reducción de los salarios reales y los gastos de consumo público, mientras que en Uruguay ambas variables sufrieron un desgaste moderado.

Los países que al final de los años ochenta todavía bregaban duramente con la recesión y la inestabilidad (Argentina, Brasil, Panamá y Perú) mostraron grados de desigualdad considerablemente mayores que los que

CUADRO 7

América Latina (10 países): Desigualdad, pobreza urbana y variables macroeconómicas al final de los años ochenta en relación con los niveles anteriores a la crisis (Indices)

\begin{tabular}{|c|c|c|c|c|c|c|c|c|c|c|c|c|c|}
\hline Países & Años & Años base & $\begin{array}{c}\text { Fase } \\
\text { macro }^{\mathrm{a}}\end{array}$ & $\begin{array}{l}\text { Aplicación de } \\
\text { reformas de política } \\
\text { significativas }\end{array}$ & $\begin{array}{l}\text { Desigualdad } \\
\text { (coeficiente } \\
\text { Gini) }\end{array}$ & $\begin{array}{l}\text { Pobreza } \\
\text { urbana } \\
\text { (incidencia) }\end{array}$ & PIB & $\mathrm{INRpc}^{\mathrm{b}}$ & $\mathrm{CGpc}^{\mathrm{c}}$ & $\mathrm{EFNA}^{\mathrm{d}}$ & $\mathrm{SR}^{\mathrm{e}}$ & $\operatorname{SMR}^{\mathrm{f}}$ & $\mathrm{TCR}^{\mathrm{g}}$ \\
\hline Argentina & 1990 & $(1980=100)$ & DyR & Reciente & 113 & 205 & 93 & 69 & $\ldots$ & 88 & 77 & 40 & 185 \\
\hline Brasil & 1990 & $(1979=100)$ & RNI & Parcial & 108 & 130 & 127 & 97 & 158 & 98 & 85 & 55 & 89 \\
\hline Colombia & 1990 & $(1980=100)$ & CSD & Parcial & 91 & 96 & 135 & 110 & 125 & 99 & 106 & 108 & 192 \\
\hline Costa Rica & 1990 & $(1981=100)$ & CSD & Sí & 103 & 138 & 128 & 95 & 115 & 103 & 102 & 134 & 90 \\
\hline Chile & 1990 & $(1981=100)$ & CSD & Sí & 113 & 107 & 126 & 104 & 69 & 108 & 96 & 76 & 240 \\
\hline México & 1989 & $(1977=100)$ & DyR & Sí & $100 ?$ & $>95$ & 147 & 106 & 76 & 89 & 54 & 41 & 111 \\
\hline Panamá & 1989 & $(1979=100)$ & RNI & No & 116 & 111 & 116 & 95 & 99 & $\ldots$ & 108 & 93 & \\
\hline Perú & 1990 & $(1979=100)$ & RNI & Reciente & $\ldots$ & 190 & 94 & 72 & 62 & $\ldots$ & 36 & 24 & 40 \\
\hline Uruguay & 1989 & $(1981=100)$ & $\mathrm{RCP}$ & Sí & 98 & 109 & 100 & 92 & 86 & $\ldots$ & 93 & 76 & 173 \\
\hline Venezuela & 1990 & $(1981=100)$ & $\mathrm{CIN}$ & Reciente & 110 & 188 & 105 & 72 & 68 & 93 & 48 & 63 & 240 \\
\hline
\end{tabular}

a DyR: Desinflación y recuperación; RNI: Recesión debida a desequilibrios internos; CSD: Crecimiento sostenido luego de la recuperación; RCP: Recuperación después del ajuste externo; CIN: Crecimiento con inestabilidad.

${ }^{\mathrm{b}}$ INRpc: Ingreso nacional real per cápita.

${ }^{\mathrm{c}}$ CGpc: Gasto de consumo real del gobierno, per cápita.
${ }_{\text {deFNA: Indice de la proporción de la fuerza laboral no agrícola en }}$ actividades formales (lo contrario de SENA: subutilización de la fuerza laboral no agrícola por persona activa).

${ }^{\text {e }}$ SR: Salarios reales urbanos o industriales.

f SMR: Salario mínimo real.

$\mathrm{g}$ TCR: Tipo de cambio efectivo real.
${ }^{29}$ Sin embargo, si la desigualdad antes de la recesión (aproximadamente 1981) en México era aún menor que el grado observado en 1977, como se señaló anteriormente, la desigualdad después de la recuperación habría sido un tanto mayor que esa marca anterior. 
predominaban antes de la crisis. La estabilización y la recuperación en Argentina solamente produjeron alguna disminución de la desigualdad del ingreso, que de todas maneras siguió siendo alta en relación con el nivel anterior a la crisis, que a su vez era marcadamente mayor que el que prevalecía antes de los trastornos de los años setenta. Por otra parte, en los períodos de recuperación después del ajuste externo, las mejoras en la distribución del ingreso - donde se produjeron — solamente tuvieron lugar junto con incrementos de los salarios reales, como se señaló anteriormente; es menos probable que estos ocurran durante los procesos de estabilización que aún enfrentan Brasil y Perú, y no se han producido durante la actual recuperación de Panamá.

Por consiguiente, no cabe prever un mejoramiento significativo de la equidad en esos países como resultado de la estabilización y la recuperación. Aún más, el pleno despliegue de las reformas de políticas y las medidas de ajuste conexas, particularmente en el frente fiscal, todavía pueden aportar algún aumento a mediano plazo de la desigualdad del ingreso. Además, si las experiencias de Colombia y Chile se toman como ejemplo, todos estos países solo pueden aguardar una limitada atenuación de las desigualdades del ingreso más adelante, cuando logren una trayectoria de crecimiento sostenido.
En resumen, los patrones distributivos "normales" en la próxima fase de crecimiento sostenido - cuando este se materialice en la mayoría de los países latinoamericanos una vez recuperados de la crisis y sus secuelas, y se hayan completado los ajustes estructurales y desplegado las reformas de políticastienden a ser más desiguales, al menos en las zonas urbanas, que aquellos que prevalecían en las últimas etapas de la fase de crecimiento anterior, durante los años setenta.

Solamente Colombia, Costa Rica y Uruguay - $y$ aparentemente quizá también México- han logrado restablecer sus grados anteriores de desigualdad (cuadro 7). Difícilmente es por azar que esto haya sucedido en países en los que los valores de la justicia social han impregnado tradicionalmente las instituciones, los objetivos de equidad han sido incorporados en forma bastante sistemática en el diseño de las políticas durante la fase de ajuste y tanto el ajuste como las reformas de políticas han sido abordados de manera gradual y pragmática. ${ }^{30}$ Ello indica que las tendencias al incremento de la desigualdad de los ingresos primarios (antes de las correcciones que supone el gasto social público) pueden modificarse positivamente mediante el diseño y ejecución de las políticas económicas.

\section{VII}

\section{Perspectivas de alivio a la pobreza}

Aun sin cambios significativos en la distribución relativa del ingreso, ${ }^{31}$ el crecimiento económico hará disminuir la pobreza absoluta; de manera más rápida al menos según las estimaciones de los economistas si se usan líneas constantes de pobreza; con más parsimonia si se considera normativamente más apropiado el desplazamiento de las líneas de pobreza con el progreso societal.

El historial de los años setenta, esbozado anteriormente, muestra que la pobreza urbana disminuyó solo en las economías de rápido crecimiento, que mantuvieron

\footnotetext{
${ }^{30}$ El método gradual se abandonó en México en la última fase del proceso de reformas, pero en circunstancias en que este proceso quedó supeditado a la incorporación del país al Tratado de Libre Comercio de América del Norte (NAFTA), salto estratégico que, cuando se lleve a cabo, cambiará radicalmente las condiciones estructurales de la economía mexicana y, entre ellas, las estructuras distributivas.

${ }^{31}$ Incluida, indudablemente, la invariabilidad de la composición de los hogares y de sus estrategias laborales y de utilización de los recursos, lo que es un supuesto sumamente artificial.
}

o redujeron la concentración del ingreso de los hogares. En Colombia, México y Venezuela, donde mejoró la equidad, la reducción de la pobreza urbana reveló elasticidades de $-0,5$ a - 1 con relación al incremento del ingreso real per cápita y de - 0,4 a - 2 con respecto a los salarios reales. En Brasil, donde no se produjo mejora significativa alguna en la concentración del ingreso, esas elasticidades fueron mucho más bajas (cuadro 8).

La recesión y la recuperación en los años ochenta dejó a la mayoría de los países latinoamericanos con una mayor incidencia a veces abismal de pobreza en las zonas urbanas que antes de la crisis. Solo Colombia y posiblemente México pudieron poner fin a sus respectivas fases de recuperación con menor pobreza urbana que antes de la recesión, en ambos casos debido a una disminución de la desigualdad (cuadro 7).

Las estimaciones existentes sobre la pobreza rara vez permiten diferenciar con nitidez los períodos recesivos 
de los de recuperación. Cuando ello sucede, los efectos benéficos de la recuperación en la pobreza parecen más débiles que los efectos negativos de la recesión anterior. En Uruguay la elasticidad de la pobreza respecto del ingreso real en la recuperación de 1986-1989 fue -2 , mientras que durante la recesión había sido -3. En Argentina la desinflación combinada con recuperación disminuyó la pobreza tan elásticamente (-4) como la recesión la había incrementado, pero la recuperación misma era entonces muy incipiente. En Venezuela, por otra parte, la consumación de la recuperación ni siquiera impidió que la pobreza aumentara más.
En otros casos (Brasil en 1979-1987, Costa Rica en 1981-1988, Chile en 1980-1987 y Perú en 19791986) la culminación de la fase de recuperación dejó la economía con un grado más alto de desigualdad y una mayor incidencia de pobreza urbana. En Costa Rica ni siquiera el crecimiento sostenido después de 1988 pudo evitar el incremento de la pobreza urbana tras la liberalización de los precios (cuadro 8).

En la mayoría de los casos los salarios reales al final de la recuperación eran menores que antes de la crisis, lo que ayuda a explicar el débil efecto de la recuperación en la pobreza. Aunque en Argentina

CUADRO 8

América Latina: Cambios en la pobreza urbana y su relación con los cambios en la concentración del ingreso y en el ingreso real en diferentes períodos

\begin{tabular}{|c|c|c|c|c|c|c|c|c|c|}
\hline \multirow{2}{*}{ Países } & \multirow{2}{*}{ Períodos } & \multirow{2}{*}{$\begin{array}{c}\text { Cambios en } \\
\text { la concentración } \\
\text { del ingreso }\end{array}$} & \multicolumn{4}{|c|}{ Variación (\%) } & \multicolumn{3}{|c|}{$\begin{array}{l}\text { Elasticidad de la pobreza } \\
\text { urbana en relación con: }\end{array}$} \\
\hline & & & $\begin{array}{l}\text { Pob. } \\
\text { urbana }\end{array}$ & $\mathrm{INRpc}^{\mathrm{a}}$ & $\mathrm{SR}^{\mathrm{b}}$ & $\mathrm{SMR}^{\mathrm{c}}$ & $\mathrm{INR}^{\mathrm{d}}$ & SR & SMR \\
\hline \multicolumn{10}{|c|}{ I. Períodos de crecimiento en los años setenta } \\
\hline Brasil & $1970-1979$ & M & -14 & 67 & 48 & -1 & $-0,2$ & $-0,3$ & 14 \\
\hline Colombia & $1970-1980$ & $\mathrm{D}$ & -21 & 44 & 17 & 27 & $-0,5$ & $-1,2$ & $-0,8$ \\
\hline México & $1970-1984$ & $\mathrm{D}$ & -30 & 31 & 15 & -20 & $-1,0$ & $-2,0$ & 1,15 \\
\hline Venezuela & 1970-1981 & $\mathrm{D}$ & -30 & 71 & $\ldots$ & -3 & $-0,4$ & $-0,4$ & 10 \\
\hline \multicolumn{10}{|c|}{ II. Períodos de recesión y recuperación en los años ochenta } \\
\hline \multirow[t]{3}{*}{ Argentina } & $1980-1986$ & I & 71 & -23 & 7 & 47 & $-3,1$ & 10 & 1,5 \\
\hline & $1986-1990$ & I & 52 & -15 & -22 & -64 & $-4,0$ & $-2,4$ & $-0,8$ \\
\hline & 1990-1991 & $\ldots$ & -22 & 5 & -7 & 39 & $-4,4$ & 3,1 & $-0,6$ \\
\hline \multirow[t]{2}{*}{ Brasil } & $1979-1987$ & I & 13 & 3 & 19 & -27 & 4,2 & 0,7 & $-0,5$ \\
\hline & $1987-1990$ & I & 15 & -6 & -29 & -26 & $-2,5$ & $-0,5$ & $-0,6$ \\
\hline Colombia & 1980-1986 & D & - & 5 & 12 & 13 & - & $-0,1$ & - \\
\hline Costa Rica & $1981-1988$ & I & 31 & -5 & 16 & 27 & $-6,5$ & 1,9 & 1,1 \\
\hline Chile & $1980-1987$ & I & 14 & -13 & -5 & -31 & $-1,1$ & $-2,8$ & $-0,5$ \\
\hline México & $1977-1984$ & D & $-6^{\mathrm{b}}$ & 14 & -34 & -40 & $-0,4$ & $-0,2$ & 0,2 \\
\hline \multirow{2}{*}{ Panamá } & $1979-1986$ & I & -3 & 23 & 14 & -6 & $-0,1$ & $-0,2$ & 0,5 \\
\hline & 1986-1989 & $\ldots$ & 13 & -22 & -1 & -1 & $-0,6$ & -13 & -13 \\
\hline Perú & $1979-1986$ & $\ldots$ & 29 & -7 & -5 & -39 & $-4,1$ & $-5,8$ & $-0,7$ \\
\hline \multirow[t]{2}{*}{ Uruguay } & 1981-1986 & I & 56 & -19 & -13 & -14 & $-3,0$ & $-4,3$ & $-4,0$ \\
\hline & 1986-1989 & $\mathrm{D}$ & -29 & 13 & 6 & -12 & $-2,1$ & $-4,8$ & 2,4 \\
\hline \multirow[t]{2}{*}{ Venezuela } & 1981-1986 & I & 39 & -31 & -19 & 6 & $-1,3$ & $-2,1$ & 6,5 \\
\hline & 1986-1990 & $\mathrm{D}$ & 32 & 3 & -41 & -19 & 9,4 & $-0,8$ & $-1,7$ \\
\hline \multicolumn{10}{|c|}{ III. Períodos de crecimiento al final de los años ochenta } \\
\hline Colombia & $1986-1990$ & $\mathrm{D}$ & -3 & 4 & -5 & -5 & $-0,7$ & 0,6 & 0,6 \\
\hline Costa Rica & $1988-1990$ & $\mathrm{D}$ & 5 & -2 & 2 & 5 & $-2,8$ & 2,5 & 1,0 \\
\hline Chile & $1987-1990$ & $\mathrm{D}$ & -8 & 18 & 11 & 27 & $-0,4$ & $-0,7$ & $-0,3$ \\
\hline
\end{tabular}

Fuente: Cuadro 5.

a INRpc: Ingreso nacional real per cápita.

${ }^{\mathrm{b}}$ SR: Salarios reales urbanos o industriales.

${ }^{\mathrm{c}}$ SMR: Salario mínimo real.

d INR: Ingreso nacional real. 
y Brasil -al término de los respectivos programas heterodoxos de estabilización- y en Costa Rica los salarios reales fueron más elevados, ese hecho de por sí parece haber sido compensado por otros factores que incrementaron la desigualdad y, en el primer caso, particularmente por la caída del ingreso real per cápita. Al contrario, en Colombia y Panamá el aumento de los salarios reales ha reforzado la recuperación del ingreso real en impedir el incremento de la pobreza urbana. Tal no fue el caso de México, donde los salarios reales en 1984 eran apreciablemente más bajos que antes de la crisis (cuadro 8).

Por otra parte, los escasos períodos de crecimiento observados al final de los años ochenta (1986-1990 en Colombia y 1987-1990 en Chile), muestran elasticidades similares con respecto al ingreso real per cápita $(-0,7$ y $-0,4$, respectivamente) a las registradas en los años setenta en las economías de rápido crecimiento, donde disminuía la desigualdad del ingreso. Solo en Chile, sin embargo, la reducción de la pobreza ha sido más elástica con respecto a los salarios reales que con relación al ingreso real, como sucedió en todos los casos en los años setenta (cuadro 8).

\section{VIII Conclusiones}

Después de superar las dificultades del decenio de 1980, los países de América Latina se lanzan a una nueva era de crecimiento potencial con arreglo a una modalidad diferente de desarrollo y un nuevo estilo de intervención estatal. Los ajustes para absorber tanto los cambios exógenos como los inevitables en materia de disponibilidad y utilización de recursos y los cambios estructurales todavía en curso, han dejado en la mayoría de las sociedades latinoamericanas la impronta de una distribución más desigual del ingreso y una mayor incidencia de la pobreza entre su gente. Las raras excepciones son el resultado de un esfuerzo deliberado y persistente en favor de la equidad en el diseño y la ejecución de las políticas económicas. Además, las perspectivas de aliviar la pobreza solamente a través del crecimiento, sin mejorar la distribución relativa del ingreso y sin vigorosas políticas sociales, parecen tan lejanas como para causar desaliento y ser contraproducentes para la integración social y, en definitiva, para el crecimiento sostenido (CEPAL, 1990).
Las migraciones del campo a la ciudad continuarán ejerciendo presión sobre la capacidad de las economías de aliviar la pobreza urbana. Si la experiencia de los dos últimos decenios (Altimir, 1991) constituye un indicio de lo que pudiera suceder, en los países relativamente menos urbanizados con alta incidencia de pobreza en las áreas rurales los migrantes rurales pobres pueden engrosar la cantidad de pobres urbanos a un ritmo equivalente a 1,3 a $2 \%$ al ano de incremento absoluto.

Sintetizando todos estos datos, es probable, por una parte, que los países que logran recuperarse hasta llegar al crecimiento a plena capacidad modifiquen su capacidad de reducir la pobreza urbana en el corto plazo y requieran una expansión relativamente mayor de la actividad económica que en la fase de recuperación para cada punto porcentual de reducción de la pobreza. Por otra parte, el crecimiento en el mediano plazo sin una reducción de la desigualdad del ingreso representaría un lento proceso de mitigación de la pobreza: más lento que en los casos de elevado crecimiento y mejoramiento de la equidad en los años setenta, y más lento que durante los recientes períodos de crecimiento en Colombia y Chile, donde también mejoró la distribución del ingreso.

Habida cuenta de las escasas perspectivas de que los ingresos primarios se vuelvan menos desiguales, inclusive bajo la tutela de las políticas económicas, el mejoramiento de la equidad y particularmente la reducción de la pobreza absoluta tendrán que depender mucho más de las políticas sociales y de su eficacia. Sin embargo, con recursos fiscales reducidos o todavía presionados por la carga de la deuda, el margen para las transferencias por concepto de prestaciones sociales se limitará casi exclusivamente a proporcionar un sistema básico de seguridad social, dándose más espacio a los gastos sociales que puedan considerarse inversiones en recursos humanos.

Los avances que en definitiva tengan lugar en la estructura de distribución del ingreso dependerán de la difusión de las mejoras de la productividad y de su apropiación efectiva por los hogares. Las transformaciones estructurales en curso tienden a incrementar la productividad del capital y la productividad total de los factores, con lo que se mejora la productividad laboral 
en la economía en general. Sin embargo, para que la distribución del ingreso mejore en función de los incrementos diferenciales de productividad se necesitan tres condiciones. Primeramente, debe ampliarse el empleo en actividades formales o modernas, y los incrementos de productividad, a una proporción mayor de la fuerza de trabajo, absorbiendo de esa forma el subempleo. En segundo lugar, las mejoras en materia de productividad deben traducirse realmente en aumentos proporcionales de los salarios. Por último, deberá elevarse en forma espectacular el capital por trabajador de la fuerza laboral que permanezca en el sector informal, la pequeña empresa y el sector tradicional de la economía. ${ }^{32}$

Para ello, así como para aumentar la productividad del capital en general, es necesario incrementar las calificaciones de los diferentes segmentos de la fuerza laboral, y al mismo tiempo reestructurar la disponibilidad de calificaciones para mejorar las capacidades tecnológicas del sistema productivo en general. Para lograrlo y asegurar su sustentación a largo plazo, se necesitarán considerables inversiones en recursos humanos (educación, capacitación y readiestramiento, nutrición y salud) para complementar las inversiones en capital fijo (CEPAL, 1992b). Aún más, en la medida en que pueda preverse una mayor contribución de aquéllos a la productividad total de los factores, en un plazo suficientemente largo, existe cierto margen para sustituir la inversión en capital físico por inversión en capital humano.

Satisfacer esos requerimientos supone considerables recursos de inversión, que habrán de originarse y manejarse parcialmente en el mercado, pero también deberán en parte ser recogidos y asignados por el Estado. Por lo demás, para que las mayores calificaciones se reflejen en el ingreso de los trabajadores, las estructuras de remuneraciones deberán enfrentarse al desafío de ser, al mismo tiempo, institucionalizadas y flexibles.

32 Quizá deberá duplicarse para el caso de quienes permanezcan en esas actividades, lo que sin embargo exigiría mucho menos capital que el requerido para cada puesto de trabajo creado en las actividades más modernas o de grandes empresas.
La absorción eficiente de capital por los subempleados, el acceso verdaderamente generalizado a la capacitación y su aplicación eficaz a la producción, la correspondencia entre las contribuciones a la productividad y los ingresos, demandan todos mejoras organizativas importantes a nivel de la empresa y profundas reformas institucionales de las políticas públicas.

La reducción de la pobreza estructural va por la misma vía que el mejoramiento general de la distribución del ingreso pero plantea obstáculos diferentes, para que las políticas sean eficaces. Por una parte, el capital físico necesario puede ser inferior que en el caso de las actividades modernas, pero el desnivel de calificaciones es mayor. Por otra parte, las políticas públicas eficaces son más exigentes en materia de organización y creatividad institucional. Por último, los correctivos deben abordar todo el círculo vicioso de circunstancias que reproducen la pobreza de generación en generación.

Las estrategias para mejorar la equidad deben tener en cuenta esas diferencias. El diseño de las políticas sociales como ha sido la práctica habitual —de manera tal que el acceso se restringe más que nada a los estratos que se hallan por encima de la línea de pobreza, para los cuales esas políticas pueden ponerse en práctica con más facilidad, y "se tira por la borda" a los pobres_- puede conducir a un mayor progreso de un segmento integrado de la sociedad y ratificar de hecho la desintegración de los estratos más pobres en una subclase segregada. En el otro extremo, una estrategia unilateral que se centre solamente en los pobres puede debilitar aún más los estratos bajos y medios de la población, donde se ubica una reserva abundante de calificaciones, cohesión social y dinamismo político. Lo que se necesita es una estrategia de "dos niveles", en que se reconozcan las diferencias existentes entre la población pobre y los grupos de trabajadores que no lo son en términos de posibilidades, capacidad de respuesta y deterioro de las condiciones de vida, y apunte a integrar ambos universos en una sociedad única y dinámica.

\section{Bibliografía}

Abugattas, Javier y Dabid R. Lee (1991): The Economic Crisis, Policy Reforms and the Poor in Peru during the 1970's and the 1980's, trabajo presentado al Seminar on Macroeconomic Crises, Policy Reforms and the Poor in Latin America, Cali, Colombia, 1 al 4 de octubre.

Altimir, Oscar (1979): La dimensión de la pobreza en América Latina, Cuadernos de la CEPAL, $\mathrm{N}^{\circ} 27$, Santiago de Chile, CEPAL. Publicación de las Naciones Unidas, $\mathrm{N}^{\circ}$ de venta: 5.81.II.0.48

(1982): The Extent of Poverty in Latin America, World Bank Staff Working Papers, $N^{\circ}$ 522, Washington, D.C., Banco Mundial.
(1986): Estimaciones de la distribución del ingreso en la Argentina, 1953-1980, Desarrollo económico, vol. 25, № 100, Buenos Aires, Instituto de Desarrollo Económico y Social (1987): Income distribution statistics in Latin America and their reliability, The Review of Income and Wealth, series 33, $\mathrm{N}^{\circ}$ 2, New Haven, CT, International Association for Research in Income and Wealth.

(1991): Latin American Poverty in the Last Two Decades, trabajo presentado al Seminar on Macroeconomic Crises, Policy Reforms and the Poor in Latin America, Cali, Colombia, 1 al 4 de octubre. 
(1992): Cambios en las desigualdades de ingreso y en la pobreza en América Latina, trabajo presentado al Fifth Interamerican Seminar on Economics, Buenos Aires, 8 al 9 de mayo, National Bureau of Economic Research, Inc. Pontificia Universidad Católica de Río de Janeiro, Instituto Torcuato Di Tella.

Banco Mundial (1991): World Development Report 1991. The Challenge of Development, Washington, D.C., Oxford University Press.

Beccaria, Luis A. (1991): Distribución del ingreso en la Argentina: explorando lo sucedido desde mediados de los setenta, Desarrollo económico, vol. 31, $\mathrm{N}^{\circ} 123$, Buenos Aires, Instituto de Desarrollo Económico y Social.

Beccaria, Luis y Alberto Minujin (1991): Sobre la medición de la pobreza: enseñanzas a partir de la experiencia argentina, Working Paper $\mathrm{N}^{\circ} 8$, Buenos Aires, Fondo de las Naciones Unidas para la Infancia (UNICEF).

Bianchi, Andrés, Robert Deblin y Joseph Ramos (1985): External Debt in Latin America. Adjustment Policies and Renegotiation, Boulder, Colorado, Lynne Rienner Publishers, Inc./CEPAL, Naciones Unidas.

(1987): El proceso de ajuste en la América Latina, 1981-1986, El trimestre económico, vol. 54 (4), $\mathrm{N}^{\circ}$ 216, México, D.F., Fondo de Cultura Económica, S.A. de C.V.

Canitrot, Adolfo (1981): Teoría y práctica del liberalismo. Política antiinflacionaria y apertura económica en la Argentina, 19761981, Desarrollo económico, vol. 21, № 82, Buenos Aires, Instituto de Desarrollo Económico y Social.

Canitrot, Adolfo y Silbia Junco (1992): Apertura y condiciones macroeconómicas: el caso argentino, serie de documentos de trabajo, $\mathrm{N}^{\circ} 108$, Washington, D.C., Banco Interamericano de Desarrollo (BID).

CePal (1979): América Latina en el umbral de los años 80 (E/ CEPAL/G.1106), Santiago de Chile, noviembre.

(1986): Crisis económica y políticas de ajuste, estabilización y crecimiento, Cuadernos de la CePAL, $\mathrm{N}^{\circ} 54$, Santiago de Chile. Publicación de las Naciones Unidas, $\mathrm{N}^{\circ}$ de venta: S.86. II.G.12.

(1988): Antecedentes estadísticos de la distribución del ingreso. México, 1950-1977, Serie distribución del ingreso, $\mathrm{N}^{\circ} 7$ (LC/G.1445), Santiago de Chile.

(1990): Transformación productiva con equidad. La tarea prioritaria del desarrollo de América Latina y el Caribe en los años noventa (LC/G.1601-P), Santiago de Chile, marzo. Publicación de las Naciones Unidas, $\mathrm{N}^{\circ}$ de venta: S.90.II.G.6.

(1991a): Magnitud de la pobreza en América Latina en los años ochenta, Estudios e informes de la CEPAL, $\mathrm{N}^{\circ} 81$ (LC/G.1653-P), Santiago de Chile. Publicación de las Naciones Unidas, $\mathrm{N}^{\circ}$ de venta: S.91.II.G.10.

(1991b): La equidad en el panorama social de América Latina durante los años ochenta (LC/G.1686), Santiago de Chile. (1991c): Una estimación de la magnitud de la pobreza en Chile 1990 (LC/R.1069), Santiago de Chile.

(1991d): Estabilización y equidad en América Latina en los ochenta (LC/R.1132), Santiago de Chile.

(1992a): El perfil de la pobreza en América Latina a comienzos de los años 90 (LC/L.716(Conf.82/6)), Santiago de Chile.

(1992b): Equidad y transformación productiva: un enfoque integrado (LC/G.1701/Rev.1-P), Santiago de Chile. Publicación de las Naciones Unidas, $\mathrm{N}^{\circ}$ de venta: S.92.II.G.5. (1993): Panorama social de América Latina. Edición 1993 (LC/G.1768), Santiago de Chile.

Cumby, R. y R. Lebich (1987): On the definition and magnitude of recent capital flight, D. Lessard y J. Williamson (eds.), Capital Flight and Third World Debt, Washington, D.C., Institute for International Economics (IIE).
Fanelli, José María, Roberto Frenkel y Guillermo Rozenwurcel (1990): Growth and Structural Reform in Latin America. Where We Stand, Buenos Aires, Centro de Estudios de Estado y Sociedad (CEDES).

Ffrench-Davis, Ricardo y Dagmar Raczynski (1987): The Impact of Global Recession on Living Standards, Notas técnicas CIEPLAN, $\mathrm{N}^{\circ}$ 97, Santiago de Chile, Corporación de Investigaciones Económicas para Latinoamérica (CIEPLAN).

Figueroa, Adolfo (1992): Social Policy and Economic Adjustment in Peru, trabajo presentado a la Conference on Poverty and Inequality in Latin America, Washington, D.C., Brookings Institution/Diálogo Interamericano, julio.

García, Norberto E. (1991): Reestructuración, ahorro y mercado de trabajo, Investigaciones sobre empleo, $\mathrm{N}^{\circ} 34$, Ginebra, Oficina Internacional del Trabajo (oIT/Programa Regional del Empleo para América Latina y el Caribe (PREALC).

Heskia, Isabel (1980): Distribución del ingreso en el Gran Santiago, 1957-1979, Documento serie investigación, N 53, Santiago de Chile, Universidad de Chile, Departamento de Economía, octubre.

Hoffmann, Rodolfo (1992): Crise econômica e pobreza no Brasil no periodo 1979-90, Brasil, Universidade de São Paulo/Escola Superior de Agricultura "Luiz de Queiroz"/Departamento de Economia e Sociologia Rural, julio.

Londoño, Juan Luis (1990): Income distribution during the structural transformation. Colombia 1938-1988, tesis de doctorado, Harbard University, mimeo.

Lustig, Nora (1992): Mexico: The Remaking of an Economy, Washington, D.C., The Brookings Institution.

Márquez, Gustavo (1992): Poverty and social policies in Venezuela, trabajo presentado a la Conference on Poverty and Inequality in Latin America, Brookings Institution/Diálogo Interamericano, Washington, D.C., Caracas, Instituto de Estudios Superiores de Administración, mimeo.

Márquez, Gustavo y Joyita Mukherjee (1991): Distribución del ingreso y pobreza en Venezuela, Caracas, Instituto de Estudios Superiores de Administración, noviembre.

Melgar, Alicia (1981): Distribución del ingreso en el Uruguay, Serie investigaciones, $\mathrm{N}^{\circ} 18$, Montevideo, Centro Latinoamericano de Economía Humana (CLAEH).

Melgar, Alicia y F. Villalobos (1987): La desigualdad como estrategia, Argumentos del CLAEH, Montevideo, CLAEH

Morley, Samuel A. y Carola Alvarez (1992): Poverty and adjustment in Costa Rica, Washington, D.C., BID, Department of Economics, enero, mimeo.

Pollack, M. y A. Uthoff (1987): Pobreza y mercado de trabajo en el Gran Santiago. 1969-1985, Documentos de trabajo, $\mathrm{N}^{\circ} 299$, Santiago de Chile, OIT/PREALC.

Psacharopoulos, George y otros (1992): Poverty and Income Distribution in Latin America. The Story of the 1980s, Report $\mathrm{N}^{\circ} 11266-\mathrm{LAC}$, Washington, D.C., Banco Mundial.

Riveros, Luis A. (1985): Desempleo, distribución del ingreso y política social, Estudios Públicos, $\mathrm{N}^{\circ}$ 20, Santiago de Chile, Centro de Estudios Públicos (CEP).

Rodríguez G. Jorge (1985): La distribución del ingreso y el gasto social en Chile 1983, ILADES, Santiago de Chile.

Trejos, Juan Diego (1991): Crisis, ajuste y pobreza: la experiencia de Costa Rica en los ochenta, trabajo presentado al Seminar on Macroeconomic Crises, Policy Reforms and the Poor in Latin America, Cali, Colombia, 1 al 4 de octubre.

Williamson, John (1990): The Progress of Policy Reform in Latin America, Policy Analyses in International Economics, $\mathrm{N}^{\circ} 28$, Washington, D.C., Institute for International Economics (IIE), enero. 